\title{
Static Structural Analysis of a Reconfigurable Rigid Platform Supported by Elastic Legs
}

\section{F.F. Rudder, Jr.}

U.S. DEPARTMENT OF COMMERCE

Technology Administration

National Institute of Standards and Technology

Precision Engineering Division Manufacturing Engineering Laborator y Gaithersburg, MD 20899

QC 



\section{NISTIR 5885}

\section{Static Structural Analysis of a Reconfigurable Rigid Platform Supported by Elastic Legs}

\section{F.F. Rudder, Jr.}

U.S. DEPARTMENT OF COMMERCE Technology Administration

National Institute of Standards and Technology

Precision Engineering Division

Manufacturing Engineering Laboratory

Gaithersburg, MD 20899

June 1996

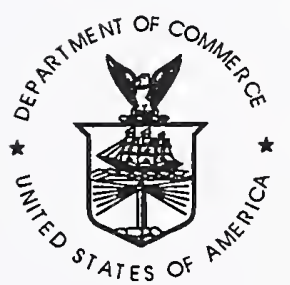

U.S. DEPARTMENT OF COMMERCE Michael Kantor, Secretary

TECHNOLOGY ADMINISTRATION

Mary L. Good, Under Secretary for Technology

NATIONAL INSTITUTE OF STANDARDS

AND TECHNOLOGY

Arati Prabhakar, Director 



\section{CONTENTS}

SECTION

1.0 INTRODUCTION

2.0 STRUCTURAL CONFIGURATION

3.0 CONSTRAINTS

4.0 ANALYSIS SUMMARY

5.0 EXAMPLES

5.1 EXAMPLE 1

5.2 EXAMPLE 2

5.3 EXAMPLE 3

5.4 EXAMPLE 4

6.0 SUMMARY

7.0 REFERENCES

Appendix: Analysis Details
PAGE

1

1

3

3

5

8

10

11

12

12

13

46 


\section{LIST OF FIGURES}

No.

Title

Page

1. Structural Configuration and Nomenclature

2. Nomenclature for Platform Joint Coordinates

3. Structural Configuration for Examples

4. Work Space Limits for Examples

5. Parameters for Example 1

6a. Example 1: Displacement Vector Field; Displacements due to Static Loads

6b. Example 1: Platform Pitch Contour Plot; Pitch due to Static Loads

7a. Example 1: Displacement Vector Field; Displacements due to Leg Lack-of-Fit

7b. Example 1: Platform Pitch Contour Plot; Pitch due to Leg Lack-of-Fit

8a. Example 1: Displacement Vector Field; Displacements due to Leg Temperature Change

8b. Example 1: Platform Pitch Contour Plot; Pitch due to Leg Temperature Change

9a. Example 1: Displacement Vector Field; Total Displacements

9b. Example 1: Platform Pitch Contour Plot; Total Platform Pitch

10. Parameters for Example 2. 
No.

11a. Example 2: Displacement Vector Field; Displacements due to Static Loads

11b. Example 2: Platform Pitch Contour Plot; Pitch due to Static Loads

12a. Example 2: Displacement Vector Field; Displacements due to Leg Lack-of-Fit

12b: Example 2: Platform Pitch Contour Plot; Pitch due to Leg Lack-of-Fit

13a. Example 2: Displacement Vector Field; Displacements due to Leg Temperature Change

13b. Example 2: Platform Pitch Contour Plot; Pitch due to Leg Temperature Change

14a. Example 2: Displacement Vector Field; Total Displacements

15. Parameters for Example 3

16a. Example 3: Displacement Vector Field; Displacements due to Leg Temperature Change

16b. Example 3: Platform Pitch Contour Plot; Pitch due to Leg Temperature Change

17a. Example 3: Displacement Vector Field; Total Displacements 
No.

Title

19a. Example 4: Displacement Vector Field; Displacements due to Static Loads

19b. Example 4: Platform Pitch Contour Plot; Pitch due to Static Loads

20a. Example 4: Displacement Vector Field; Displacements due to Leg Lack-of-Fit

20b. Example 4: Platform Pitch Contour Plot; Pitch due to Leg Lack-of-Fit

21a. Example 4: Displacement Vector Field; Displacements due to Leg Temperature Change

21b. Example 4: Platform Pitch Contour Plot; Pitch due to Leg Temperature Change

22a. Example 4: Displacement Vector Field; Total Displacements

22b. Example 4: Platform Pitch Contour Plot; Total Platform Pitch 
Conventional machine tools are characterized by stacked slideways and a series structural stiffness configuration. A new class of machine tools characterized by computer-controlled articulation of multiple legs supporting a spindle platform has emerged. Since the multiple legs represent a parallel structural stiffness configuration, this new class of machine tools is referred to as a parallel-actuator structure in contrast to the more conventional stacked-series structural configuration. A representative example of this new class of machine tools is a commercial prototype machine at the National Institute of Standards and Technology. Because of its geometric configuration, this machine tool is referred to as the NIST Octahedral Hexapod. The parallel-actuator structure of the Octahedral Hexapod is composed of multiple legs connecting the spindle platform to a rigid frame by pinned joints.

One aspect of the study of this machine is to measure the positional and machining accuracy capabilities of this member of this new class of machines. The goal of these measurements is the development an accurate, comprehensive estimate of the Octahedral Hexapod's machining errors, that is, the systematic and random differences between dimensions of part features produced by the machine and those desired.

As a basis for developing an accurate error budget for this type of machine, this report describes a tool for analyzing the machining errors produced by static deformations of the machine's platform due to the separate effects of platform loading, manufacturing errors in leg length, and temperature change in the legs.

The work reported here was sponsored by the National Advanced Manufacturing Testbed (NAMT) program of the Manufacturing Engineering Laboratory of NIST under project 8210017.

\subsection{STRUCTURAL CONFIGURATION}

The structural configuration is illustrated in Figure 1. A global axis system $(\mathrm{X}, \mathrm{Y})$ defines all joint positions for each leg supporting the rigid platform. The platform configuration is defined by the coordinates $(\mathrm{X}, \mathrm{Y}, \Theta)$ of a reference position and orientation on the platform as illustrated in Figure 1. The platform configuration $(X, Y, \Theta)$ and the coordinates of the pinned joints for each leg define the ideal or perfect length for each leg. Each leg is assumed to be a constant cross section, uniform, linearly elastic rod supported by pinned joints at each end. The physical parameters of each leg may be different.

The platform has three degrees of freedom:

- $\quad \mathrm{u}$, lateral displacement in $\mathrm{X}$ direction

- $\quad \mathrm{v}$, vertical displacement in $\mathrm{Y}$ direction

- $\theta$, rotation positive in the counterclockwise direction

The displacements are assumed small relative to the overall dimensions of the structure. 


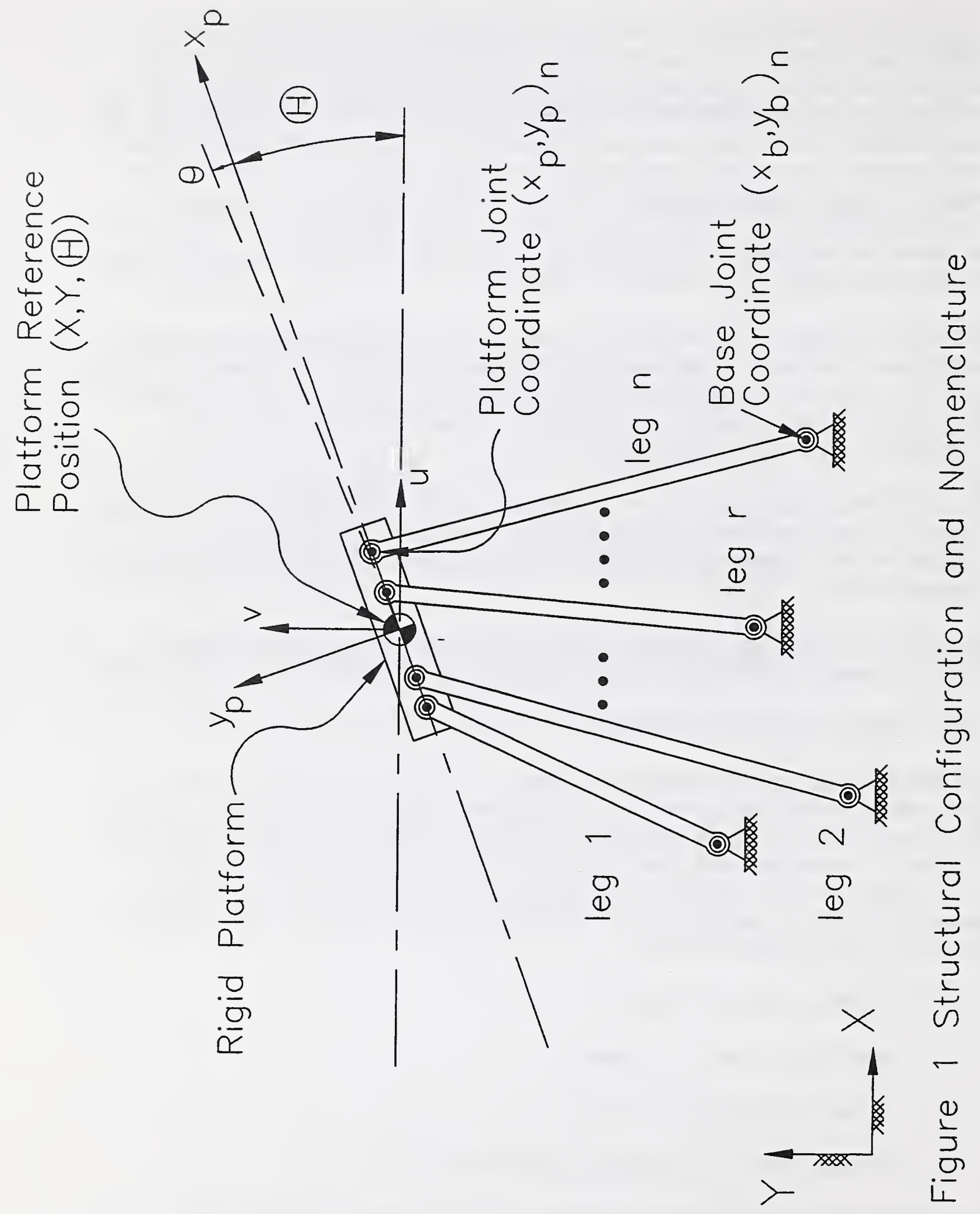


The configuration illustrated in Figure 1 represents two forms of constraint: static and geometric. The static constraint is defined by the number of non-colinear legs. For two non-colinear legs the system is a linkage and not a structure. For three non-colinear legs the structure is statically determinant. For four or more non-colinear legs the structure is statically indeterminant or redundant. That is, the structure is over constrained statically.

Geometric constraint is a result of the assumption of a rigid platform. Figure 2, illustrates the platform coordinate system and the nomenclature of the pinned joint locations on the platform. The pinned joints are assumed to be located along the $x_{p}$ axis of the platform. For any platform location $(X, Y, \Theta)$ any two joint locations define the direction of the $x_{p}$ axis. Three or more noncoincident platform joints introduce a geometric constraint.

Neither the number of struts nor the number of platform joints poses any problem for the analysis.

\subsection{ANALYSIS SUMMARY}

The detail analysis is based upon the principle of virtual work. All usual assumptions are made for small displacement, linearly elastic structural analysis.

For the interested reader, several references are listed at the end of the report. Reference 1 provides an example of a single pinned joint supported by elastic rods that is similar in approach to the analysis presented here.

Each leg of the structure is loaded by axial loads applied at the pinned joint at each end of the leg. The direction of the load is in the direction of the leg when the platform is positioned at the $(\mathrm{X}, \mathrm{Y}, \Theta)$ location.

Due to loads applied to the platform and initial strains in the legs, the reference location of the platform displaces to the location $(\mathrm{X}+\mathrm{u}, \mathrm{Y}+\mathrm{v}, \Theta+\theta)$. The analysis establishes the relationship among the displacements $(u, v, \theta)$ and the platform loading in the form

$$
[\mathrm{K}]\{U\}=\{\mathrm{P}\}+\left\{\mathrm{P}_{\eta}\right\}+\left\{\mathrm{P}_{\mathrm{T}}\right\}
$$

where:

$\{U\}=\left\{\begin{array}{l}u \\ v \\ \theta\end{array}\right\}=$ the displacement vector $\{\mathrm{P}\}=\left\{\begin{array}{l}\mathrm{P}_{X} \\ \mathrm{P}_{Y} \\ \mathrm{M}\end{array}\right\}=$ the platform loading

$\left\{P_{\eta}\right\}=\left\{\begin{array}{l}P_{\eta_{X}} \\ P_{\eta_{Y}} \\ M_{\eta}\end{array}\right\}=\begin{gathered}\text { platform loading due to "lack-of-fit" of the legs } \\ \text { (this is defined below) }\end{gathered}$

$\left\{\mathrm{P}_{\mathrm{T}}\right\}=\left\{\begin{array}{l}\mathrm{P}_{\mathrm{T}_{\mathrm{X}}} \\ \mathrm{P}_{\mathrm{T}_{\mathrm{Y}}} \\ \mathrm{M}_{\mathrm{T}}\end{array}\right\}=$ platform loading due to temperature change of the legs

$[\mathrm{K}]$ is the structural stiffness matrix. 


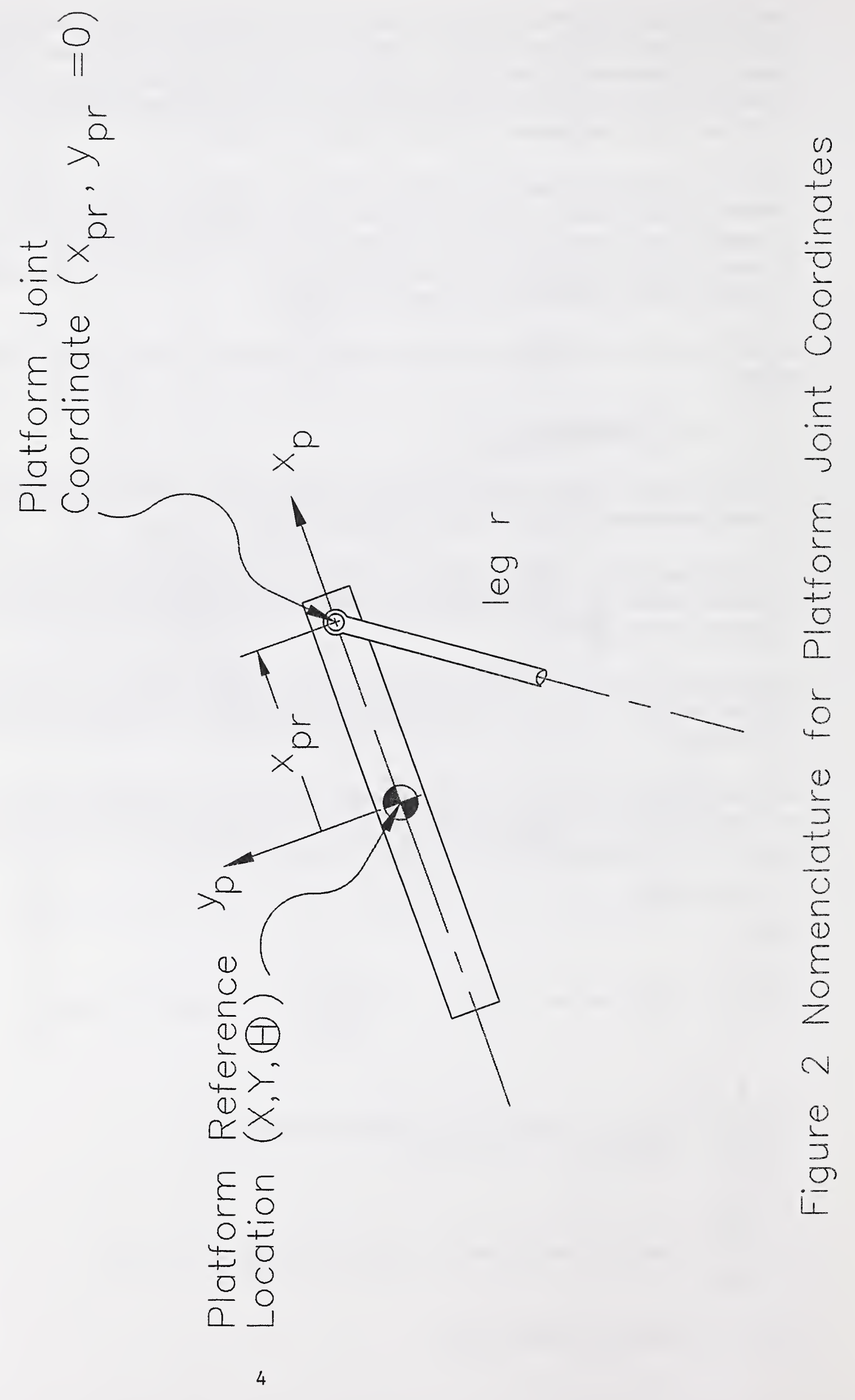


The physical aspects of "lack-of-fit" and temperature change must be clearly understood. These terms apply to the legs of the structure. As described previously, the joint locations of a leg and the platform location $(X, Y, \Theta)$ define the design or perfect leg length, $1_{r}$. The terms "lack-of-fit" and temperature change cause deviations of the actual leg length from the design leg length.

As a structural component, each leg is manufactured and measured (at a reference temperature) to determine its length. The design length is $\mathrm{l}_{\mathrm{r}}$ and the deviation from the design length is denoted as $\Delta \mathrm{l}_{\mathrm{r}}$ but it is assumed that all values of $\Delta \mathrm{l}_{\mathrm{r}}$ are determined at the same reference temperature.

Further, the analysis assumes that when the structure is assembled each leg experiences a temperature change relative to the reference temperature at which $\Delta \mathrm{l}_{\mathrm{r}}$ was determined. The sequence of structural assembly and leg temperature change is an integral assumption of the analysis.

For structural assembly, one imagines that the platform is held by a rigid fixture at the location $(\mathrm{X}, \mathrm{Y}, \Theta)$. The temperature of the assembly area is the reference temperature at which the values of $\Delta \mathrm{l}_{\mathrm{r}}$ were measured. Since each leg deviates from the design length, each leg must be forced to fit into the assembly fixture. Hence, the term "lack-of-fit". Upon completion of fitting all the legs, the legs each experience a temperature change from the reference temperature, while the platform is still rigidly held in the assembly fixture. Finally, static loads are applied to the platform and the assembly fixture is slowly released allowing the platform to displace to the location $(\mathrm{X}+\mathrm{u}, \mathrm{Y}+\mathrm{v}, \Theta+\theta)$.

Given the relationship expressed by Equation (1), it is a simple matter to invert the stiffness matrix $[\mathrm{K}]$ and solve for the displacements $\{\mathrm{U}\}$. The displacements are composed of three additive parts: those due to static loads, those due to "lack-of-fit", and those due to temperature change. The following examples illustrate these effects.

\subsection{EXAMPLES}

Figure 3 illustrates a platform supported by four legs. The structural geometry, as illustrated, is symmetric about the $\mathrm{Y}$ axis and all legs have the same cross section area, elastic modulus, and coefficient of thermal expansion. Four example calculations are presented. Each example considers 121 different structural configurations defined by placing the platform at points within a rectangular grid defined by the range $-1000 \mathrm{~mm} \leq X \leq 1000 \mathrm{~mm}$ and $1000 \mathrm{~mm} \leq \mathrm{Y} \leq 3000 \mathrm{~mm}$. A $200 \mathrm{~mm}$ spacing is used for the grid points.

For an articulated platform, each leg would be constrained for a minimum or maximum length and angular rotation limits at the pinned joints. Figure 4 illustrates a plot of the X-Y plane with eight intersecting circular arcs. Each arc represents either the minimum leg length or the maximum leg length for each leg. For these examples the values of $2350 \mathrm{~mm}$ and $3600 \mathrm{~mm}$ are used (i.e., each leg can extend over the range $2350 \mathrm{~mm} \leq 1_{\mathrm{r}} \leq 3600 \mathrm{~mm}$. The interior region defined by the eight circular arcs represents the physical locations that could be reached by the platform for these leg length restrictions. Obviously, this is a very simple-minded definition of the platform positioning since joint angle restrictions are not considered. Further, for certain leg configurations and platform orientation $\Theta$ it may be possible to reach a structural configuration that would be neutrally stable. These considerations are ignored in this analysis. Figure 4 is presented so that the reader can appreciate that plots of the deformation fields for a grid of points may include locations that may not be reachable by a practical articulated structure. 


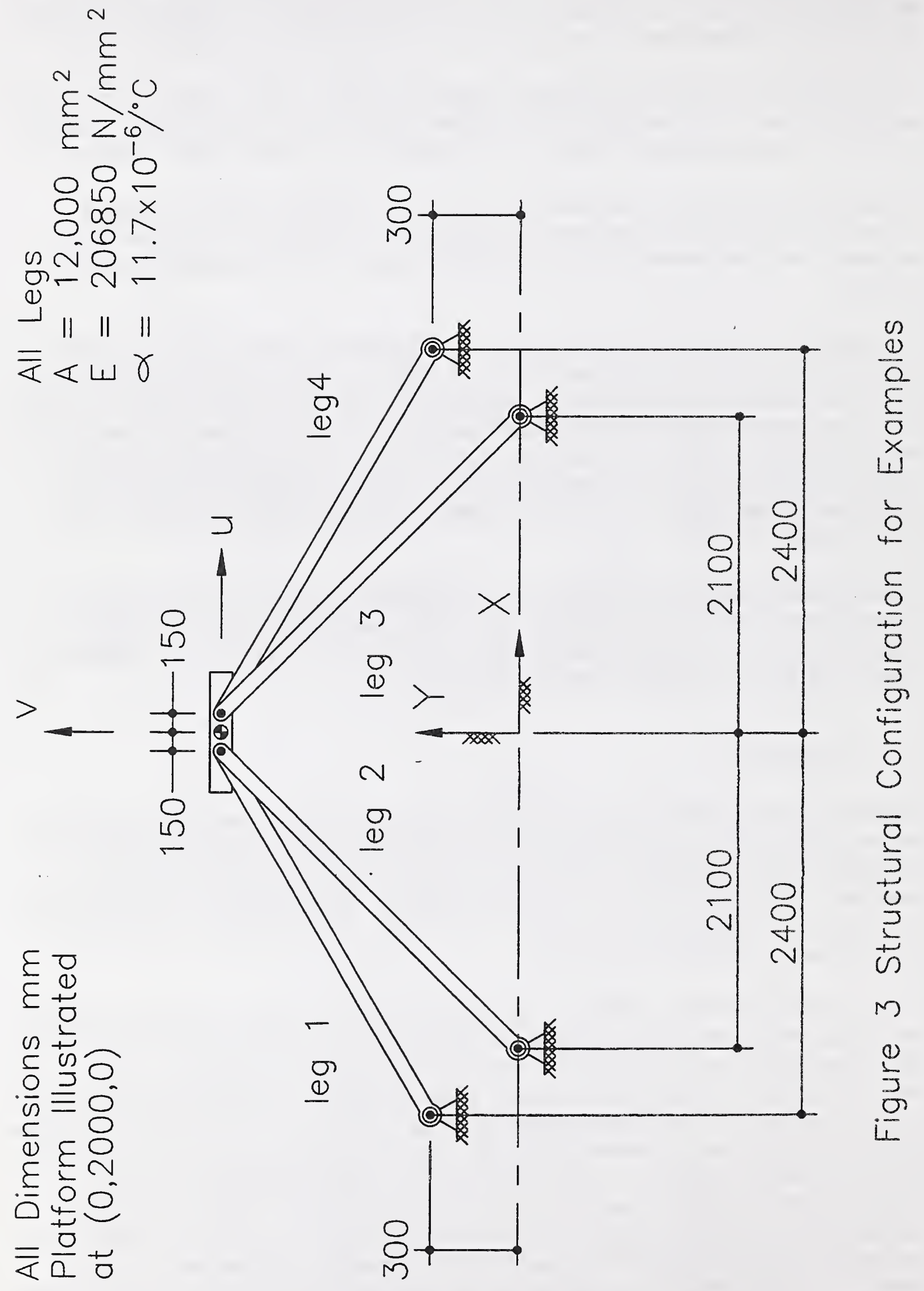




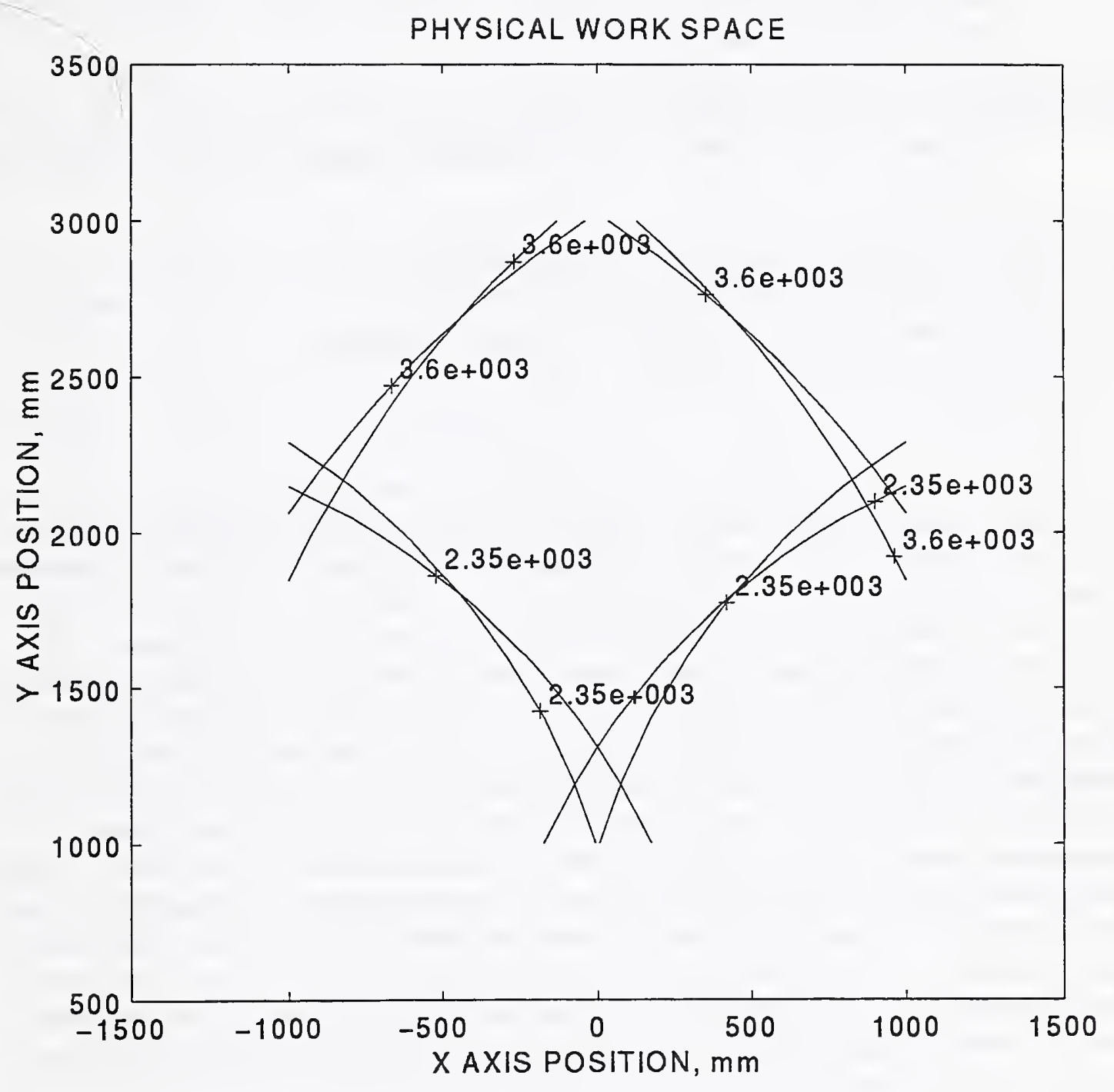

Figure 4. Work Space Iimits for Examples 
Each of the four examples are based on the structural geometry (i.e., base joint locations) and leg properties illustrated in Figure 3. The differences among the examples are as follows:

Example 1: Vertical platform loading: $P_{Y}=6672.3 \mathrm{~N}(1500 \mathrm{lbf})$

lack-of-fit of $+25.4 \mu \mathrm{m}$, all legs

temperature change of $+2^{\circ} \mathrm{C}$, all legs

platform tilt $\Theta=0^{\circ}$, all locations

Example 2: Lateral platform loading: $\mathrm{P}_{\mathrm{X}}=6672.3 \mathrm{~N}(1500 \mathrm{lbf})$

lack-of-fit of $-25.4 \mu \mathrm{m}$, all legs

temperature change of $+2^{\circ} \mathrm{C}$, all legs

platform tilt $\Theta=0^{\circ}$, all locations

Example 3: Same as Example 1 except that

leg number 1 (see Figure 3) is given a temperature change of $+5^{\circ} \mathrm{C}$ with all other legs at $0^{\circ} \mathrm{C}$

Example 4: Same as Example 1 except that the platform tilt is $10^{\circ}$.

\section{All figures for each example are included at the end of the report.}

\subsection{EXAMPLE 1}

Figure 5 illustrates the platform loading, lack-of-fit data, temperature change data, and platform tilt for this example. The leg structural data are given in Figure 3. For this example, all data are symmetric with respect to the $Y$ axis. Hence, we expect all displacement fields to be symmetric with respect to the $Y$ axis and all platform pitch fields to be asymmetric with respect to the $Y$ axis. This example illustrates the effect of structural coupling for this type of structure. The results are presented in eight figures. Four figures present vector field plots of the platform $(u, v)$ displacement at each grid location. The four figures are displacements due to static loading, displacements due to leg "lack-of-fit", displacements due to temperature change, and total displacements (i.e., the algebraic sum of the displacement fields.) For each of the vector field plots of displacement, contours are also plotted. The contours are constant levels of the displacement vector lengths. The static displacement field, the "lack-of-fit" displacement field, and the temperature displacement field are each scaled to the magnitude of the maximum vector length of the total displacement field. The platform pitch is presented as a contour plot of the platform pitch angle, $\theta$. The platform pitch is also presented for the static loads, "lack-of-fit" condition, temperature change condition and the total platform pitch. Finally, the units of the displayed quantities are length expressed in millimeters and angles expressed in arc seconds.

Figure 6a presents the vector field of displacements due to the vertical static loading. These displacements are computed using the expression $[\mathrm{K}]^{-1}\{\mathrm{P}\}$ (see Equation 1). The field is symmetric about the global $\mathrm{Y}$ axis. The structure exhibits highest stiffness along the $\mathrm{Y}$ axis. One interesting aspect of Figure 6a is the characteristic u displacement always causing a lateral platform displacement toward the $\mathrm{Y}$ axis. This obviously results from the static coupling between the (u,v) coordinates when the platform is positioned laterally in the X direction. This displacement field represents the platform positioning errors if no compensation is provided to correct for the individual strut extensions due to platform loading. 
Figure $6 \mathrm{~b}$ presents the contour plot of platform pitch due to static loads. The static stiffness coupling causes the platform to pitch due to the vertical load. When the platform is located to the left of the $Y$ axis the pitch is counterclockwise. When the platform is located to the right of the $\mathrm{Y}$ axis, this pitch is clockwise. That is, the platform pitch is asymmetric with respect to the $\mathrm{Y}$ axis.

Figure 7a presents the vector field of displacements due to the $+25.4 \mu \mathrm{m}$ "lack-of-fit" which results in all legs being installed with a compressive load so that each strut reacts on the platform with a push. These displacements are computed using the expression $[\mathrm{K}]^{-1}\left\{\mathrm{P}_{\eta}\right\}$ (see Equation 1). The displacement field of Figure 7a indicates that the positive "lack-of-fit" generally causes a positive displacement in the $\mathrm{Y}$ direction.

Figure $7 \mathrm{~b}$ presents the contour plot of platform pitch due to the "lack-of-fit" of the legs. For platform locations to the left of the $\mathrm{Y}$ axis, the pitch is counterclockwise. For platform locations to the right of the $\mathrm{Y}$ axis, the pitch is clockwise.

Figure 8a presents the vector field of displacements due to the $+2^{\circ} \mathrm{C}$ temperature change in all the legs. These displacements are computed using the expression $[\mathrm{K}]^{-1}\left\{\mathrm{P}_{\mathrm{T}}\right\}$ (see Equation 1). As explained in the analysis in the appendix, the present model considers either a uniform or linearly varying temperature distribution along the length of the leg. Hence, one may consider the $+2^{\circ} \mathrm{C}$ temperature change to represent either a constant $2^{\circ} \mathrm{C}$ change or an average (over the leg length) $2^{\circ} \mathrm{C}$ change. For this example, the temperature change effect predominately results in a platform translation in the positive $\mathrm{Y}$ direction.

Figure $8 \mathrm{~b}$ is the platform pitch contour plot for pitch due to temperature change. For platform locations to the left of the Y-axis the platform pitches counterclockwise. For platform locations to the right of the $\mathrm{Y}$-axis the platform pitches clockwise.

The reader should note the similar characteristic patterns of the vector fields between Figures $7 \mathrm{a}$ and $8 \mathrm{a}$ and the pitch contour plots of Figures $7 \mathrm{~b}$ and $8 \mathrm{~b}$. These similarities emphasize the nature of the two physical effects described by the model. As presented in the appendix, strain due to lack-of-fit and strain due to temperature are both considered as different forms of an initial strain on the structure. The lack-of-fit strains are proportional to the leg lengths for each platform position (i.e., the longer the leg the smaller the strain). The strains due to temperature change are directly proportional to the temperature change and independent of the leg lengths. For this example problem, the lack-of-fit and the temperature change data each result in a compressive load in the legs. Hence, the vector displacement fields in Figure 7a and Figure 8a both exhibit a positive displacement $v$ in the $Y$ direction. In Figure $7 a$, the displacement vectors are seen to decrease in magnitude as the $Y$ platform position increases (i.e., the legs are increasing in length). In Figure 8a, the displacement magnitudes are very nearly constant illustrating the constant strain modeled by the temperature change. Figure $8 \mathrm{a}$ also indicates a coupling between the $\mathrm{u}, \mathrm{v}$ displacements for platform positions located laterally from the $\mathrm{Y}$ axis. This coupling is also present in the Figure 7a data although not so evident as for Figure 8a. For the pitch contour plots, Figures $7 \mathrm{~b}$ and $8 \mathrm{~b}$ are very similar although the magnitudes for temperature change are slightly greater than those for the lack-of-fit. In summary, the displacements and pitch for the two initial strain effects modelled by the analysis are similar in nature to each other.

Finally, the vector displacement plot for total displacements is presented in Figure 9a. Considering the previous discussions, it is evident that for this example the $u$ component of total 
displacement is dominated by the static stiffness and the $\mathrm{v}$ component of total displacement is dominated by the temperature change.

Figure $9 \mathrm{~b}$ presents the total platform pitch contour plot for this example. This figure indicates that platform pitch is dominated by the static stiffness of the structure.

Since the greatest magnitude displacement and pitch conditions generally occur at the outer boundary of the grid points, the reader is reminded that kinematic constraints on platform positioning may prohibit locating the platform at these extreme locations. By overlaying a plot, such as Figure 4, on each of the displacement or pitch plots one can obtain a better idea of the simulated structural performance.

\subsection{EXAMPLE 2}

Figure 10 illustrates the loading condition, lack-of-fit data and leg temperature data for this example. All other data are as described for Example 1. The differences between Example 1 and the present example illustrate the effect of lateral loading instead of vertical loading and "undersize" leg lengths instead of "oversize" leg lengths. One would expect that the displacement and pitch plots for the loading to be different from Example 1. The plots for "lackof-fit" should exhibit a sign reversal for this example as compared to Example 1. The temperature change plots should be identical to those of Example 1.

Figure 11a illustrates the displacement field vector plot for the lateral loading. Compared to Figure $6 \mathrm{a}$ (Example 1) it is evident that direction of platform loading results in a characteristic change of the displacement field plot.

Figure $1 \mathrm{lb}$ illustrates the platform pitch due-to-loading and should be compared to Figure $6 \mathrm{~b}$ for the case of vertical loading. For vertical loading (Figure 6b), the platform pitch exhibits a large variation of platform pitch as the platform is positioned in the $\mathrm{X}$ coordinate for a fixed $\mathrm{Y}$ coordinate. For fixed $\mathrm{X}$ coordinate, the platform pitch shows a somewhat smaller variation as the platform is positioned in the Y coordinate. For lateral loading (Figure 11b), the opposite characteristic is predicted by the model. As the platform is positioned in the $\mathrm{X}$ coordinate for a fixed $\mathrm{Y}$ coordinate, the platform maintains an almost constant (and large) pitch angle. For a constant $\mathrm{X}$ coordinate, the platform pitch exhibits a large variation as the platform is positioned in the $\mathrm{Y}$ coordinate. As for the displacement field plot, the platform pitch for this example is distinctly different when compared to the Example 1 results.

Figure 12a illustrates the displacement field plot for the "lack-of-fit". For this example, all legs are assumed to be $25.4 \mu \mathrm{m}$ short $\left(\Delta \mathrm{l}_{\mathrm{r}}=-25.4 \mu \mathrm{m}\right)$ of the ideal length, $\mathrm{l}_{\mathrm{r}}$. As previously discussed, each leg must be placed in tension to "assemble" the structure. Hence, the "lack-of-fit" causes each leg to pull on the platform resulting in the direction of the platform displacement to be reversed from that given in Figure $7 \mathrm{a}$ (Example 1). Two comments are appropriate concerning Figures 12a and 7a. First, the contours of constant displacement magnitude are identical for both plots. That is, changing the leg lengths from "oversized" (Example 1) to "undersized" (this example) changes the displacement direction but not the magnitude of the displacement vector. Second, although the magnitudes are identical, the vectors in Figure 12a are plotted smaller than the vectors in Figure 7a. This is related to the scaling used by the software when generating the vector plots. Each plot is scaled relative to the maximum displacement magnitude of the total displacement field. Hence, the different vector lengths for Figures 7a and 12a indicate that for 
constant loading magnitude the maximum magnitude of the total displacement field is greater for lateral loading than for vertical loading.

Figure $12 \mathrm{~b}$ is the platform pitch due to the leg lack-of-fit. Comparing this plot with Figure $7 \mathrm{~b}$ for Example 1, it is evident that reversing the lack-of-fit reverses the platform pitch.

Figures $13 \mathrm{a}$ and $13 \mathrm{~b}$ are the displacement field vector plot and the platform pitch plot resulting from changing the leg temperatures $+2^{\circ} \mathrm{C}$. This is the identical condition for temperature change illustrated in Example 1 and the results are identical.

Figure $14 \mathrm{a}$ is the total displacement field vector plot for this example. Figure $14 \mathrm{~b}$ is the total platform pitch plot for this example. Comparing these results to Figures $9 \mathrm{a}$ and $9 \mathrm{~b}$ of Example 1, it is evident that the change in load direction results in dramatically different displacement and pitch characteristics of the platform.

\subsection{EXAMPLE 3}

This example is identical to Example 1 except that the temperature change for each leg is altered. For this example, leg 1 (the extreme left-hand-side leg) is given a $+5^{\circ} \mathrm{C}$ temperature change with all other legs at $0^{\circ} \mathrm{C}$ change. (For Example 1, all legs are given a $+2^{\circ} \mathrm{C}$ temperature change.) For this example, the displacements and pitch plots for both platform loading and lack-of-fit are identical to those for Example 1. These results will not be repeated for this example. The displacements and pitch for temperature change and the total displacements and total pitch are expected to differ from the corresponding results presented in Example 1.

Figure 15 illustrates the physical conditions for this example.

Figure 16a is the platform displacement field due to the unsymmetric temperature change conditions specified for the legs. The corresponding result for a symmetric temperature change (Examples 1 and 2) are given in Figures 8a and 13a. Comparing Figure 16a with Figure 8a, it is evident that the unsymmetric temperature condition results in a completely different displacement field pattern than that for the symmetric temperature condition.

Figure $16 \mathrm{~b}$ is the platform pitch contour plot for this example. Comparing this result to Figure $8 \mathrm{~b}$ for a symmetric temperature condition, it is evident that the unsymmetric heating results in a rather different pattern of platform pitch response.

It is interesting to compare Figures 11 a (displacement due to lateral load/Example 2) and Figure 16a (displacement due to $+5^{\circ} \mathrm{C}$ temperature change in leg $1 /$ this example). For both examples, the pattern of the displacement fields are quite similar both in magnitude and direction of the displacement vector. Comparing Figures $16 \mathrm{~b}$ and $11 \mathrm{~b}$, it is evident that the platform pitch response is rather different. In summary, the displacement fields look rather similar but the pitch fields are quite different.

Figures $17 \mathrm{a}$ and $17 \mathrm{~b}$ are the total displacement vector field and total platform pitch contour plots, respectively, for this example. 


\subsection{EXAMPLE 4}

This example is identical to Example 1 except that the platform is tilted $\Theta=+10^{\circ}$. The parameters for this example are illustrated in Figure 18. The platform tilt introduces an asymmetry into the structural configuration. This asymmetry is evident in all the displacement and pitch plots.

Figures 19a through $22 \mathrm{~b}$ present the displacement and pitch response for this example. The reader should compare these results with Figures 6a through $9 \mathrm{~b}$ for Example $1\left(\Theta=0^{\circ}\right)$.

\subsection{SUMMARY}

A static planar structural analysis of a rigid platform supported by elastic pinned-joint legs is described. The model estimates displacements and pitch of the platform. These displacement and pitch estimates are calculated for the separate conditions of platform loading, lack-of-fit of the legs (manufacturing errors), and temperature change (relative to a reference temperature) of the legs. The results are displayed as a vector field of platform displacements and a contour field of platform pitch. Four example conditions are presented illustrating platform static response due to separate and combined effects of loading, lack-of-fit, and temperature. 


\subsection{REFERENCES}

1. Argyris, J.H. and Kelsey, S.: Energy Theorems and Structural Analysis: Butterworths Scientific Publications, Part I §3\&4, 1960.

2. Courant, R., and Hilbert, D.: Methods of Mathematical Physics, Interscience Publishers Inc., IV §12.12, pp. 268-272, 1953.

3. Megson, T.H.G.: Aircraft Structures for Engineering Students, Edward Arnold Ltd., Chapter 4, 1984.

4. Neal, B.G.: Structural Theorems and Their Application, Pergammon Press Ltd., Ch. 3\&6, 1964.

5. Przemieniecki, J.S.: Theory of Matrix Structural Analysis, McGraw-Hill Book Company, Chapters 1,2,3. 1968.

6. Rivello, R.M.: Theory and Analysis of Flight Structures, McGraw-Hill Book Company, Chapter 6, 1969.

7. Washizu, K.: Variational Methods in Elasticity (3rd Ed.), Pergammon Press Ltd., Chapters 1, 2, 5. 1982. 


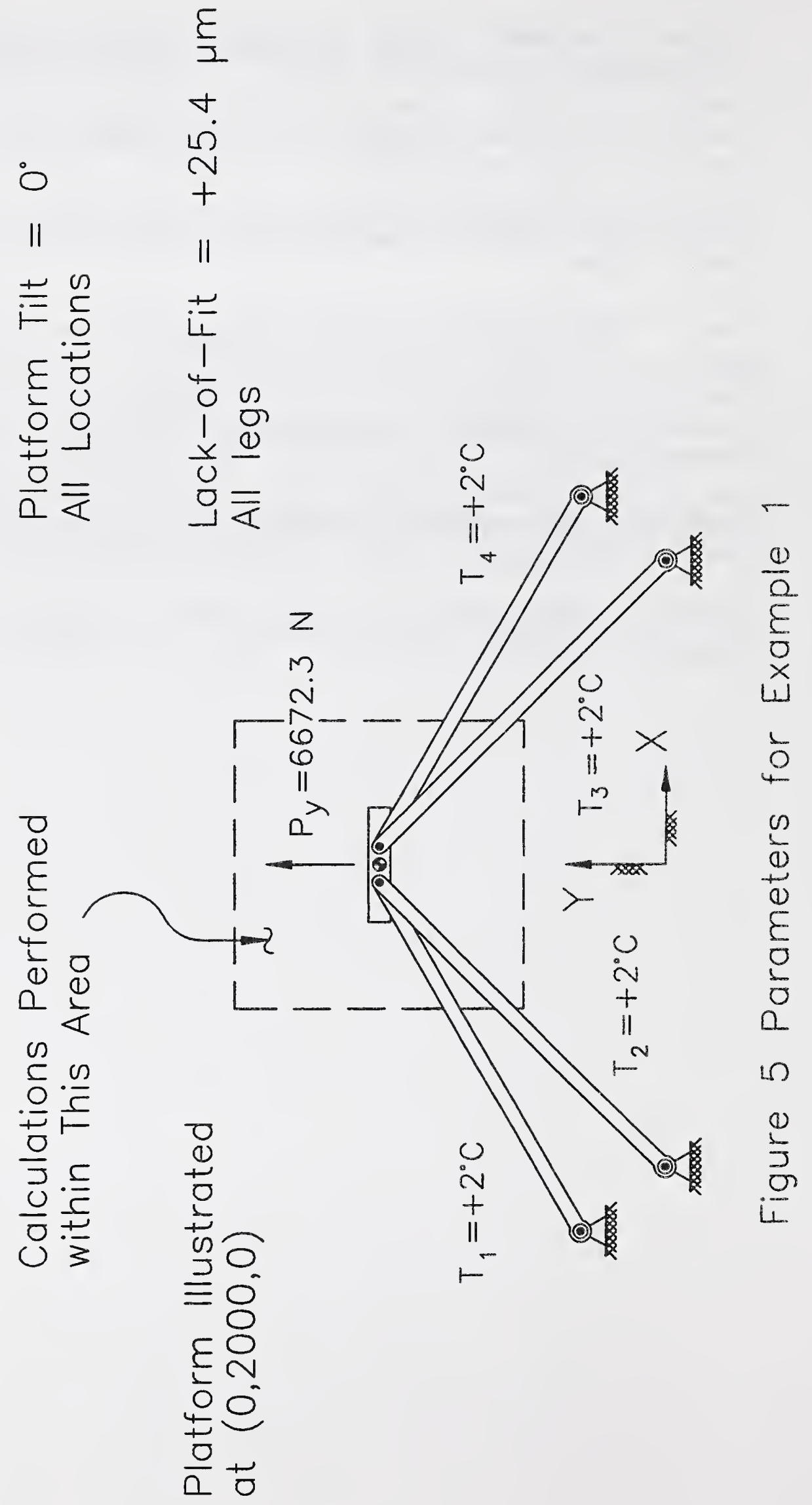




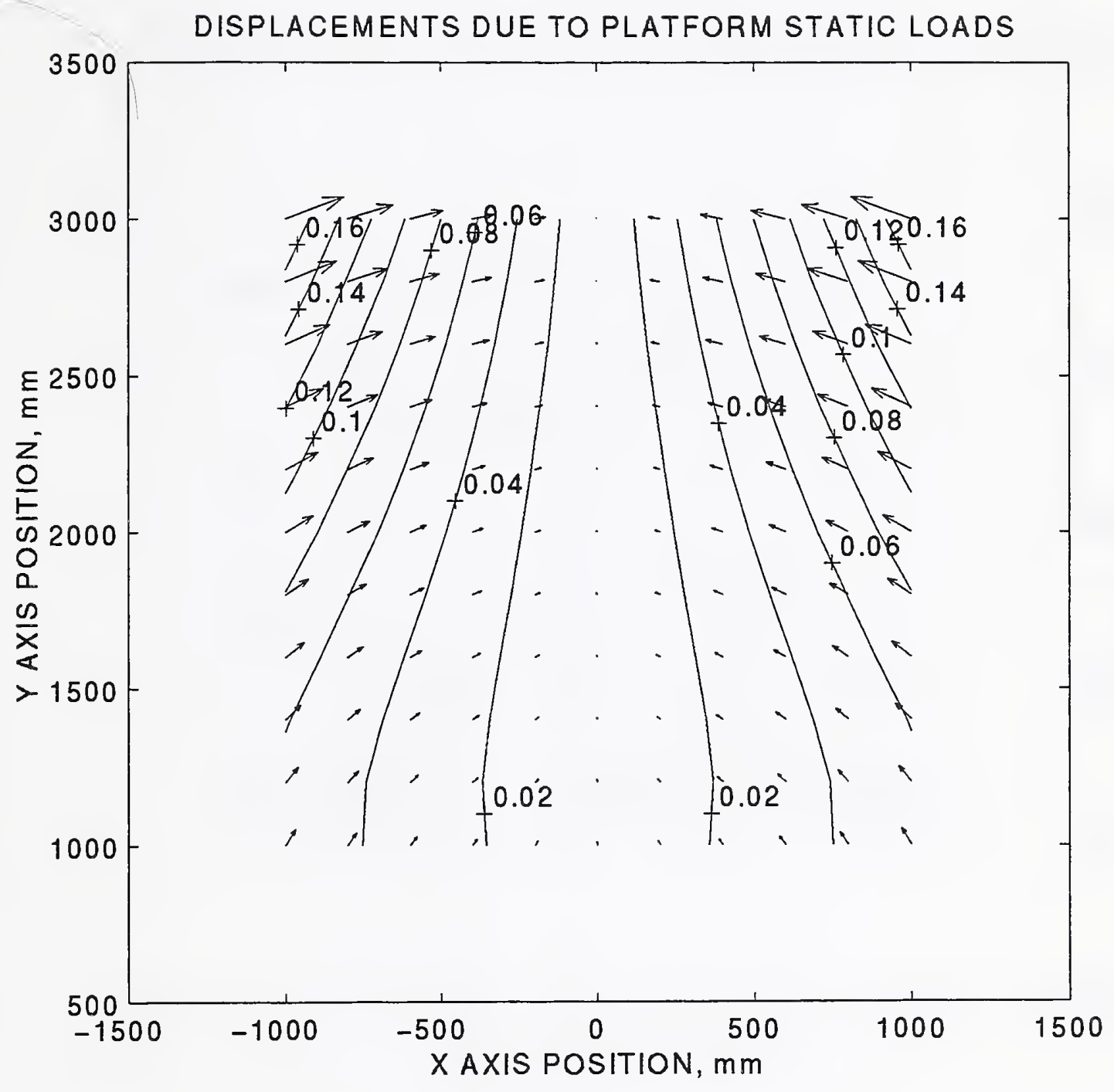

Figure 6a. Example 1: Displacement Vector Field; Displacements due to Static Loading 
PLATFORM PITCH DUE TO STATIC LOADS

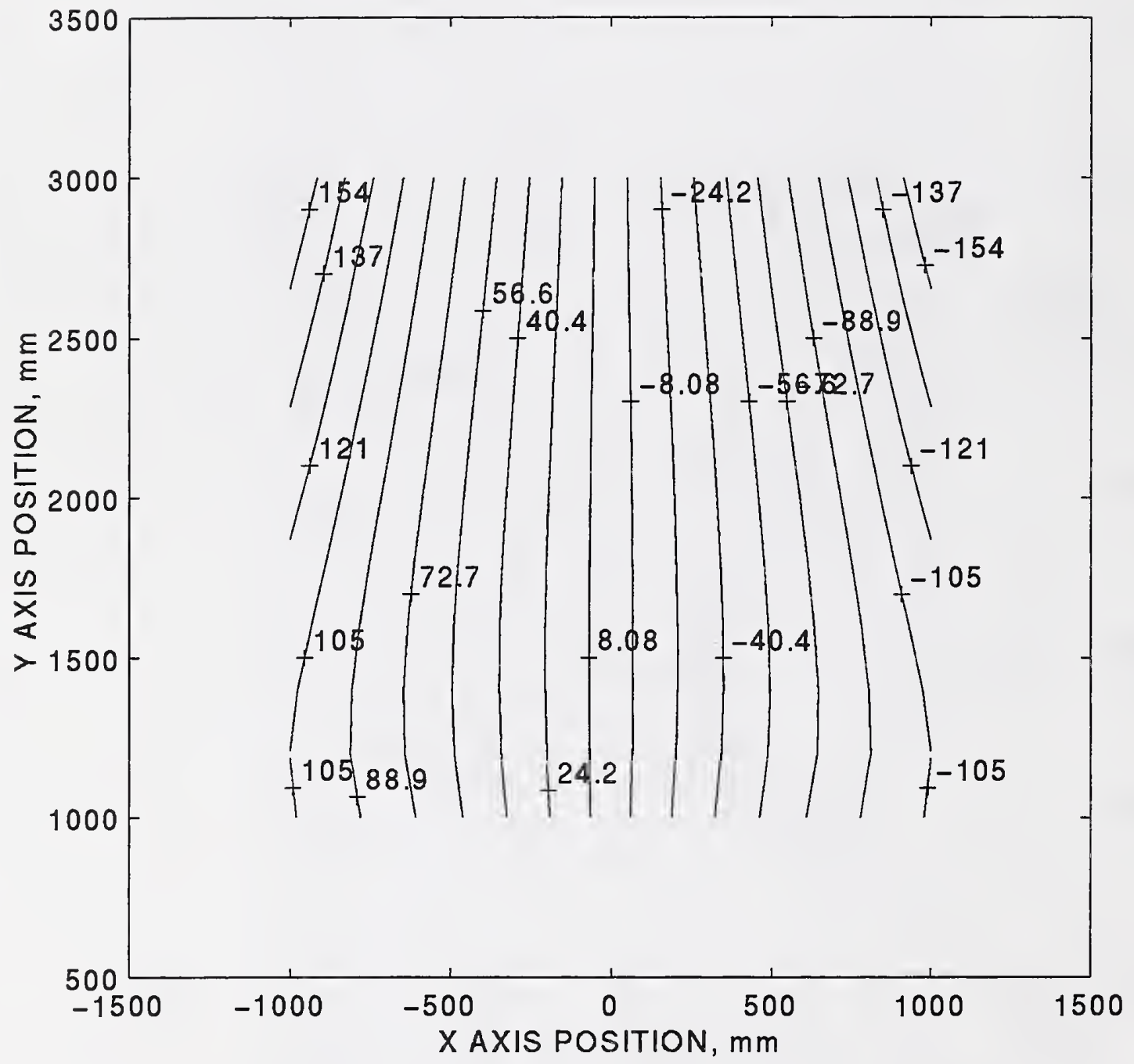

Figure 6b. Example 1: Platform Pitch Contour Plot; Pitch due to Static Loads 


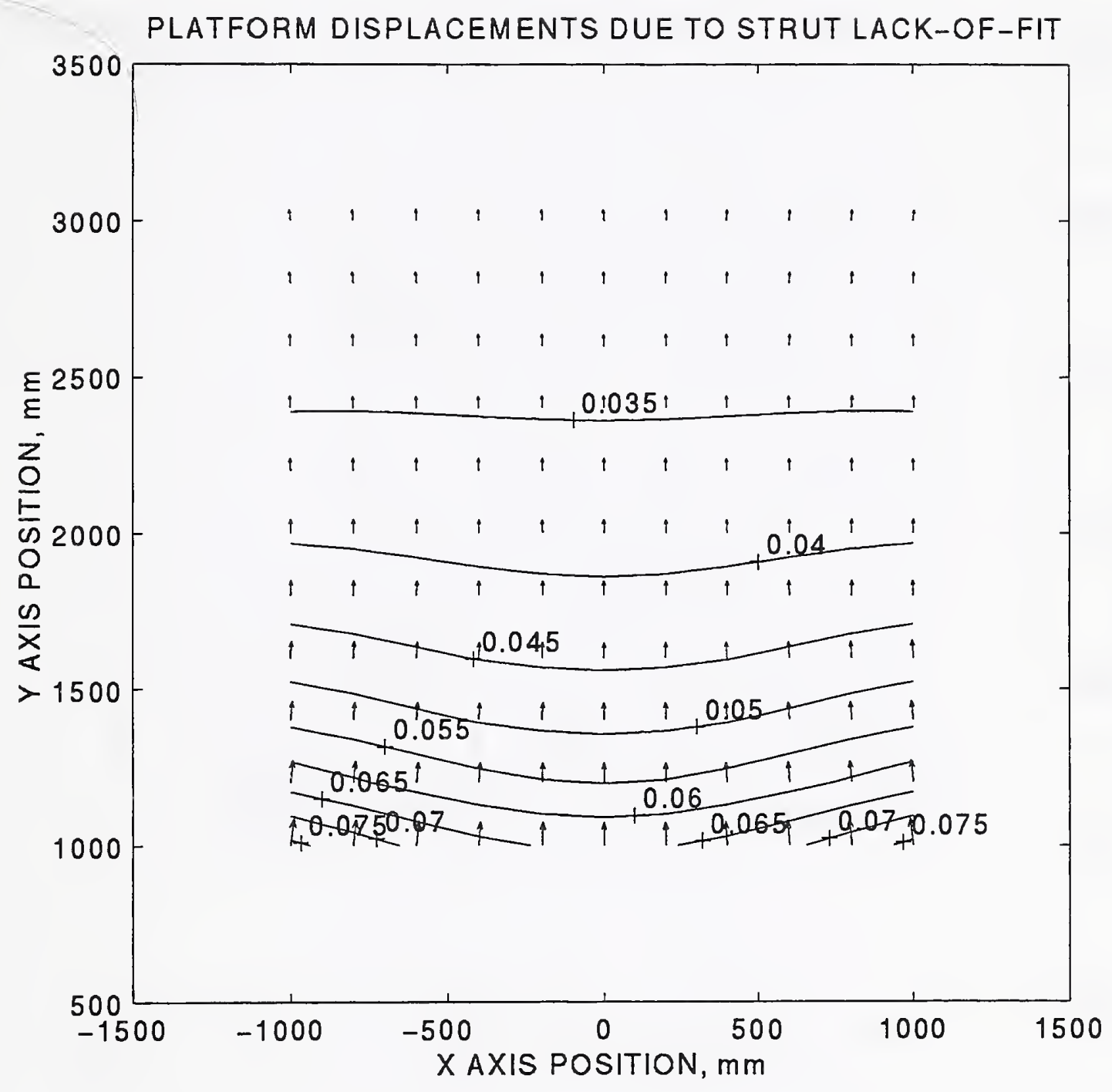

Figure 7a. Example 1: Displacement Vector Field; Displacements due to Leg Lack-of-Fit 


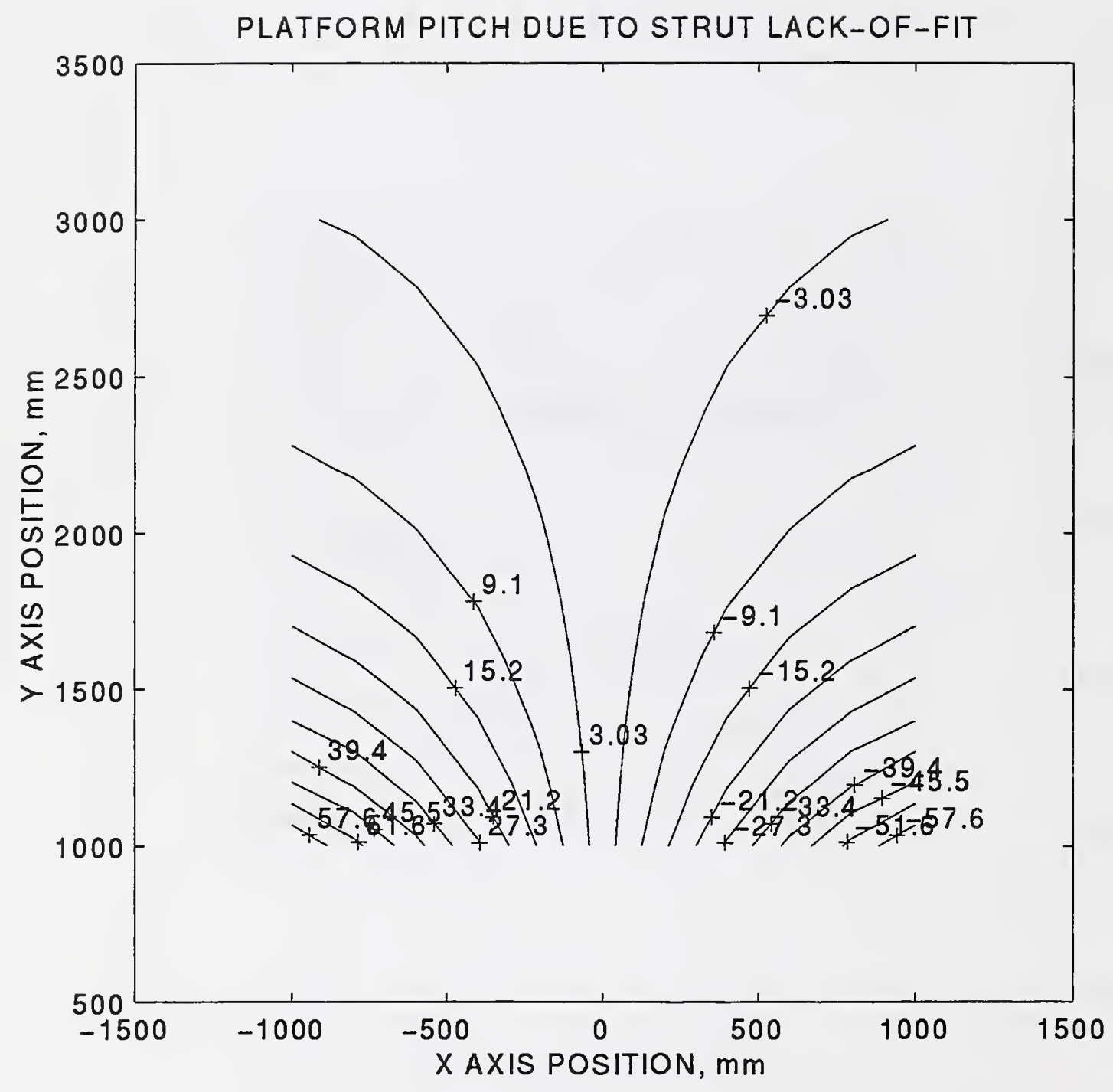

Figure 7b. Example 1: Platform Pitch Contour Plot; Pitch due to Jeg Lack-of-Fit 


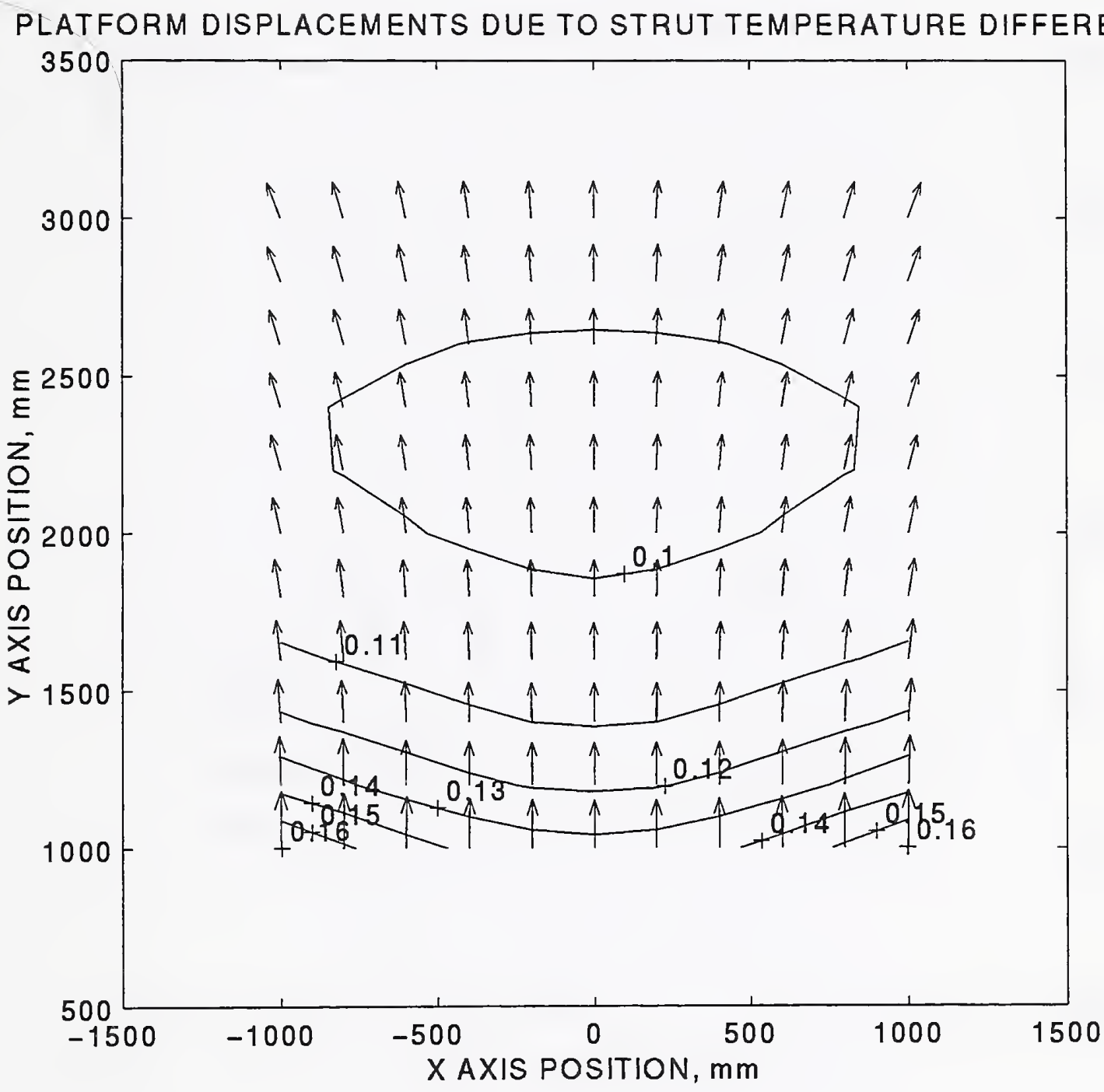

Figure 8a. Example 1: Displacement Vector Field;

Displacements due to Leg Temperature Change 


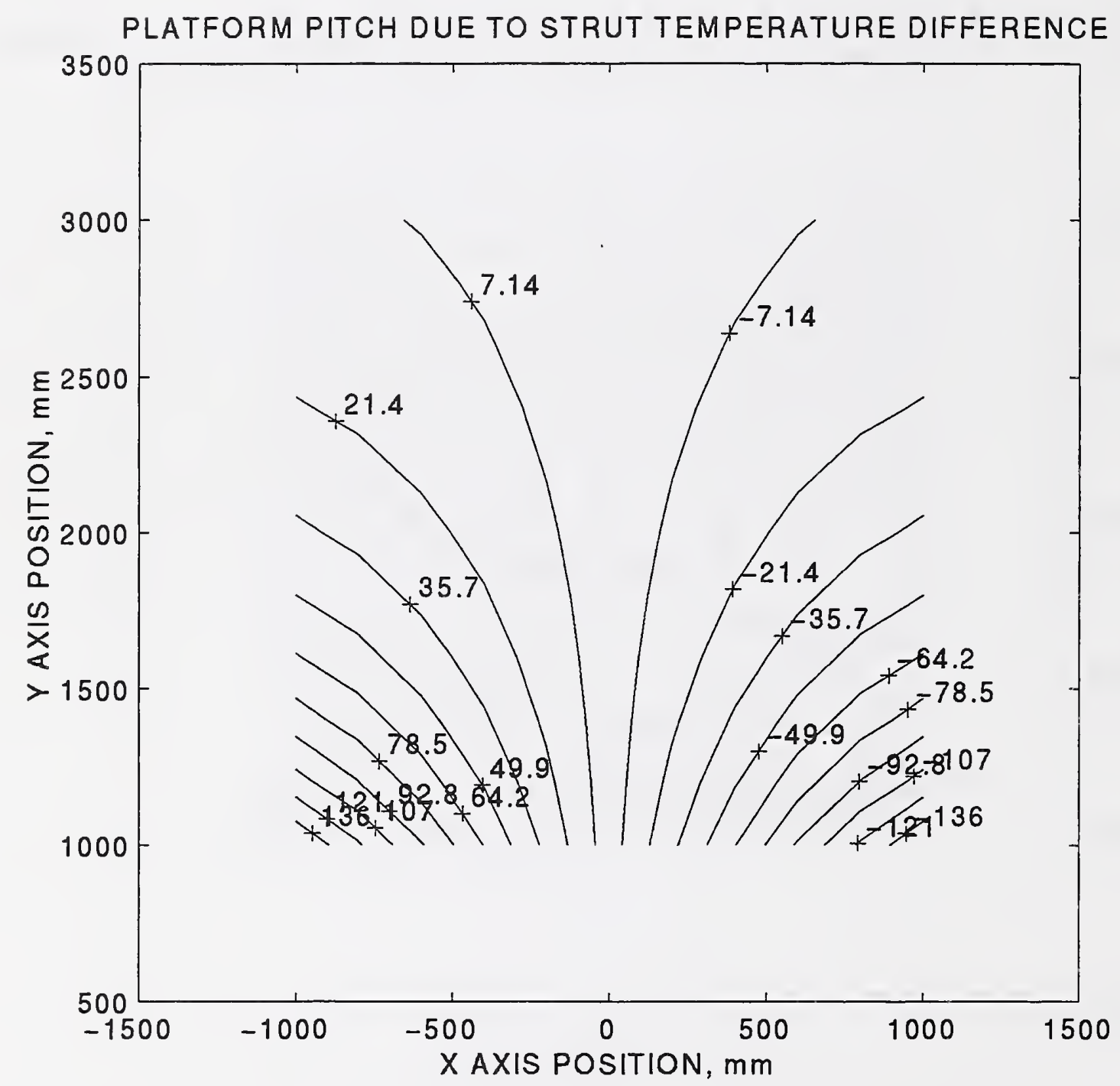

Figure 8b. Example 1: Platform Pitch Contour Plot; Pitch due to Leg Temperature Change 


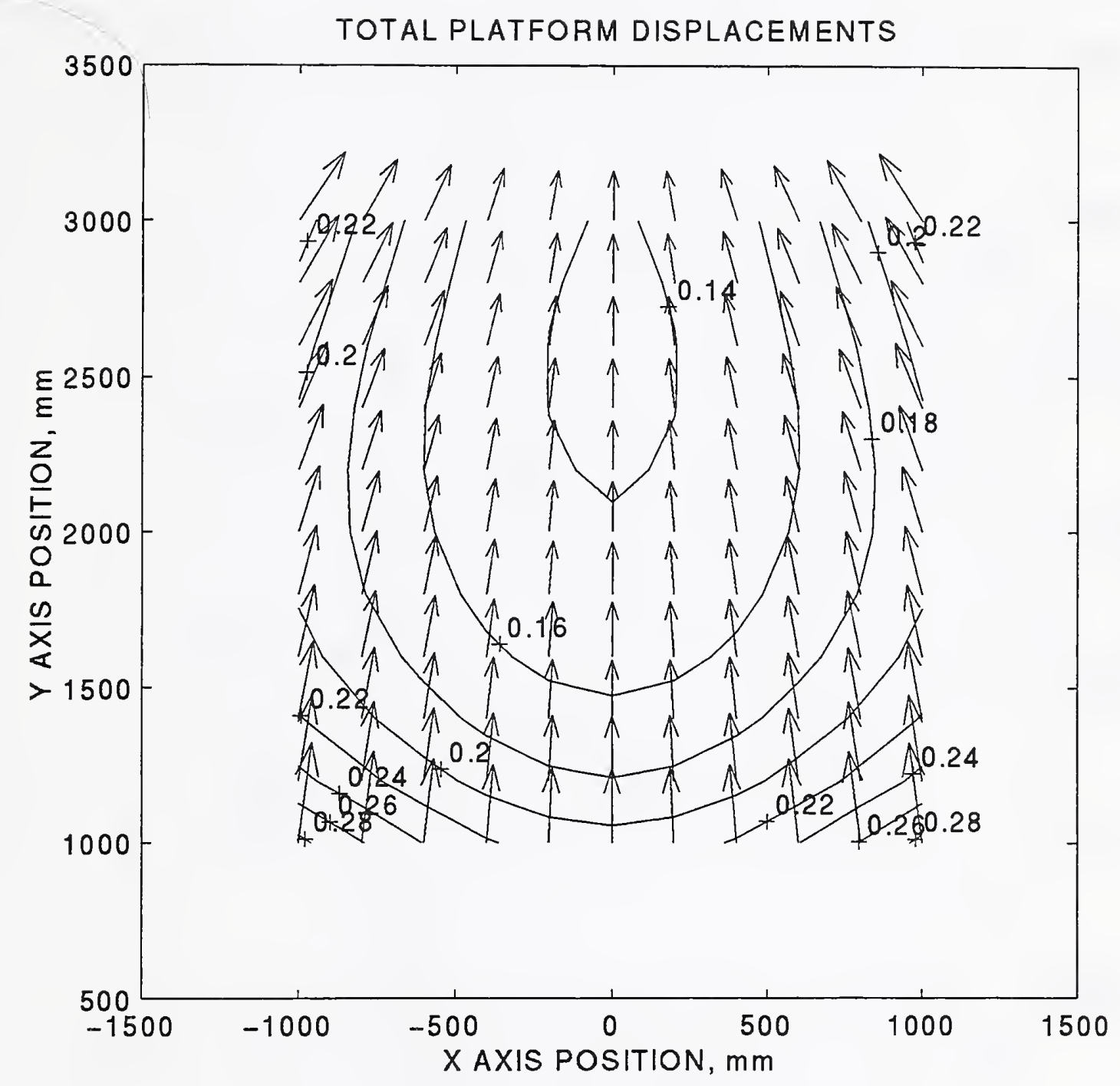

Figure 9a. Example 1: Displacement Vector Field; Total Displacements 


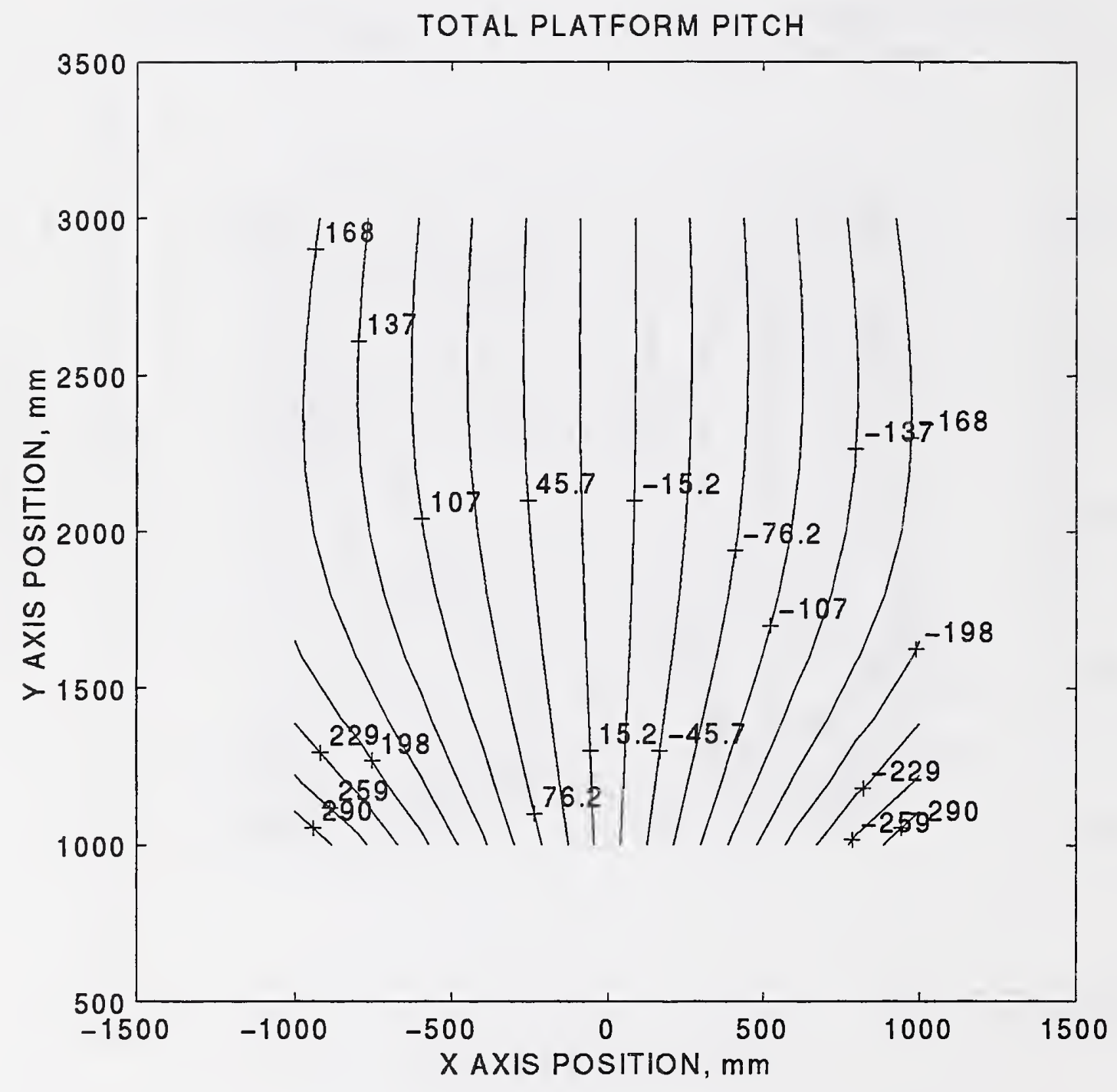

Figure 9b. Example 1: Platform Pitch Contour Plot; Total Platform Pitch 


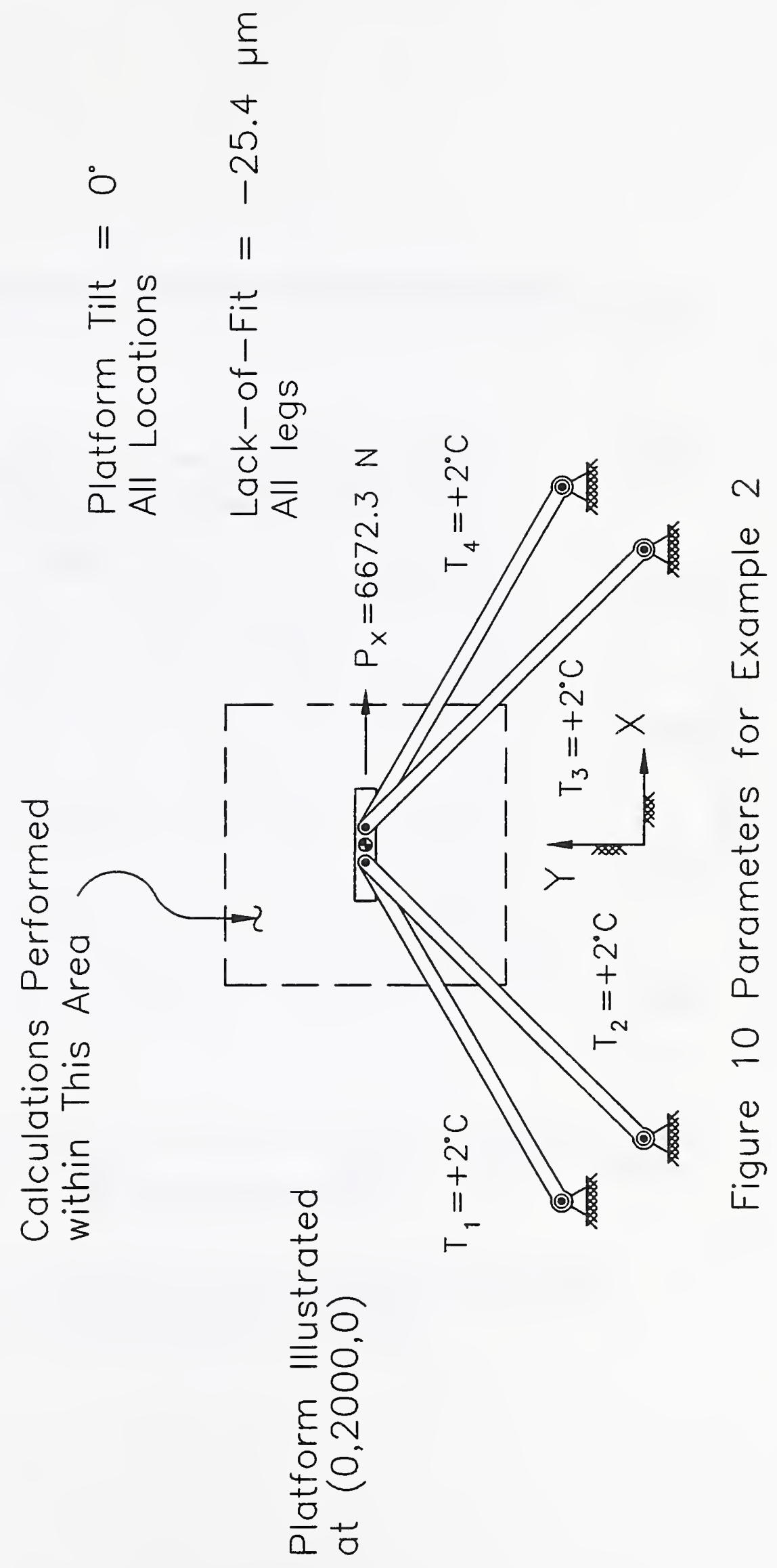




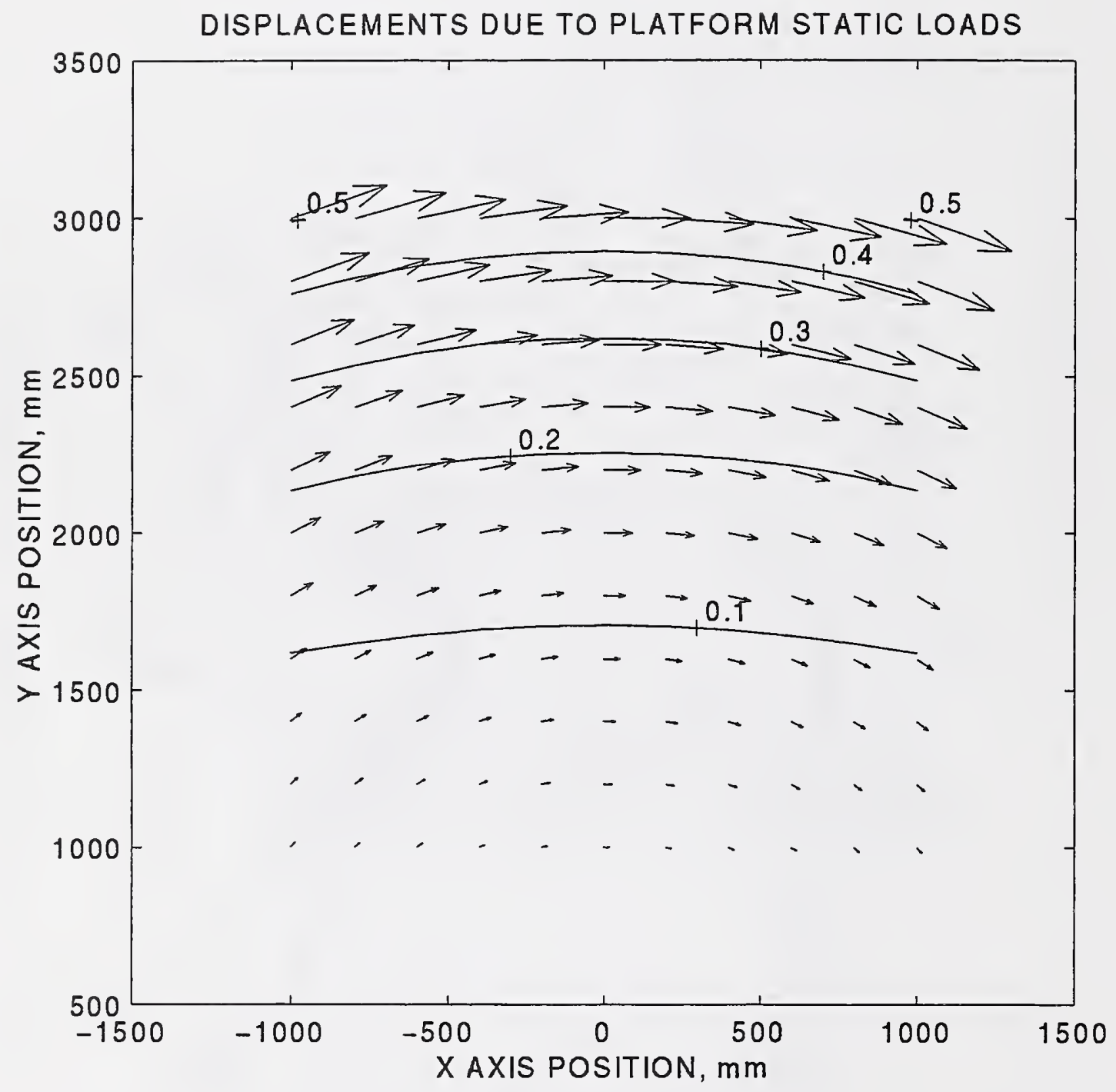

Figure 11a. Example 2: Displacement Vector Field; Displacements due to Static Loads 


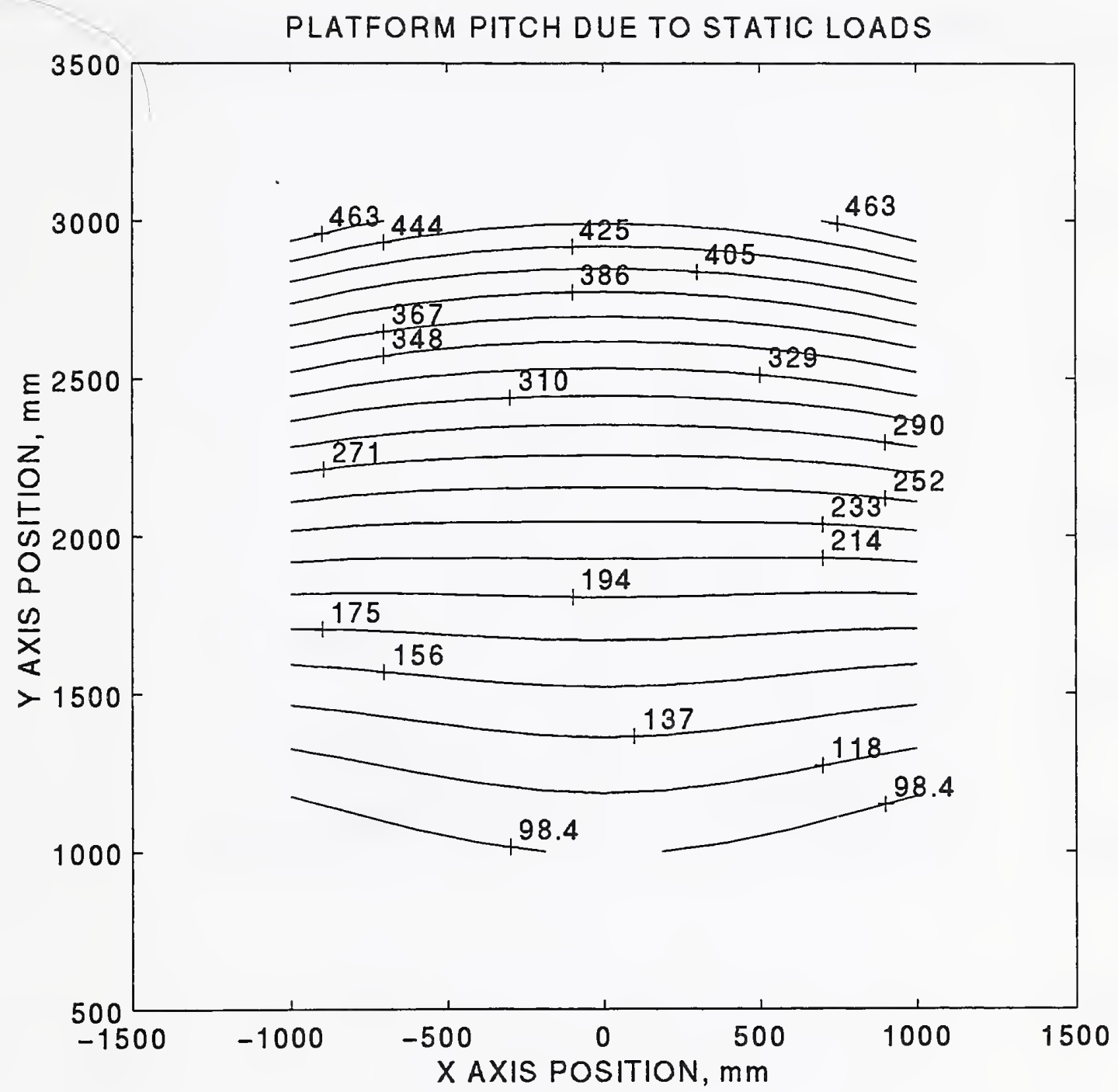

Figure 11b. Example 2: Platform Pitch Contour Plot; Pitch due to Static Loads 


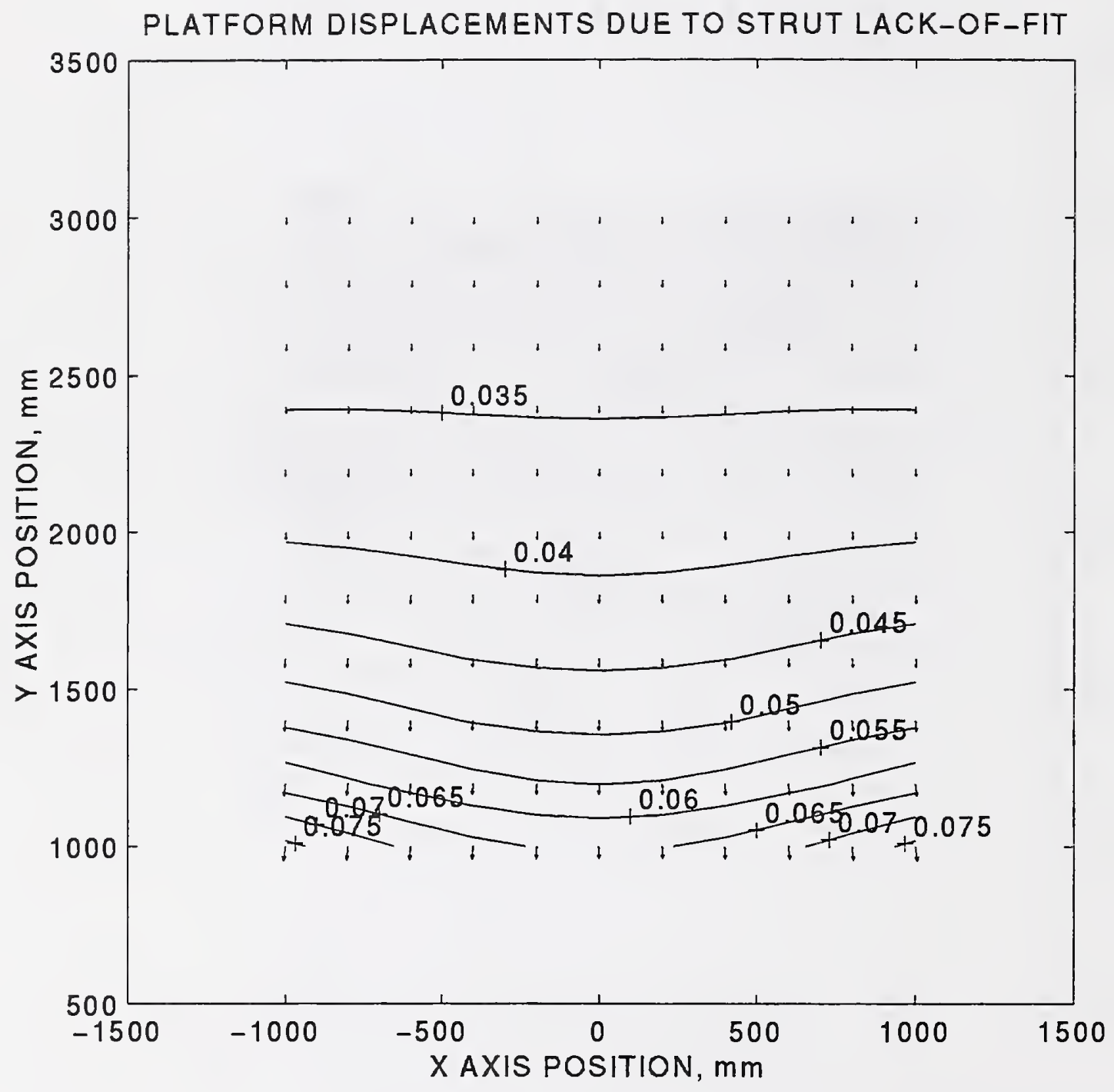

Figure 12a. Example 2: Displacement Vector Field; Displacements due to Leg Lack-of-Fit 


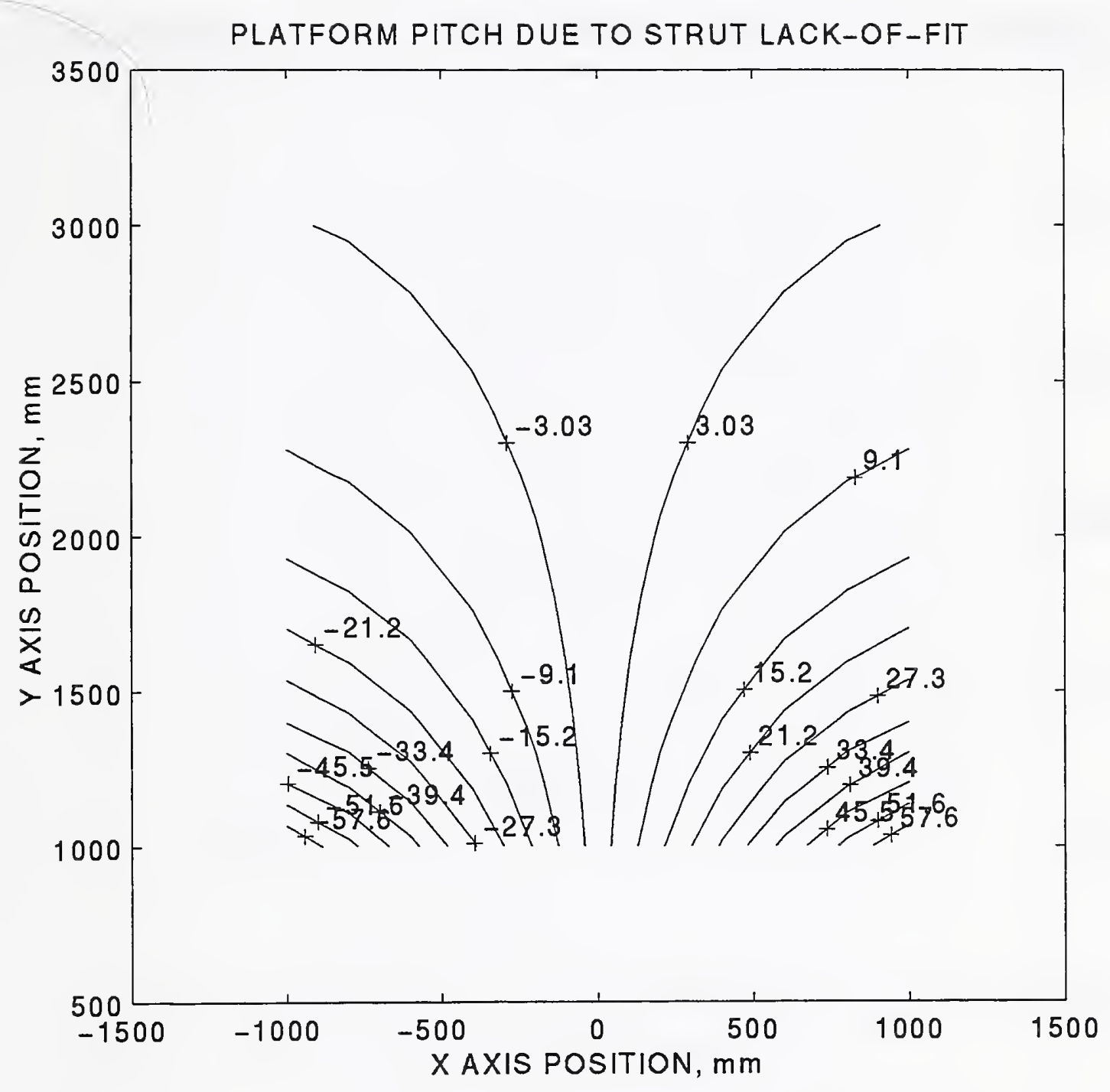

Figure 12b. Example 2: Platform Pitch Contour Plot; Pitch due to Leg Lack-of-Fit 


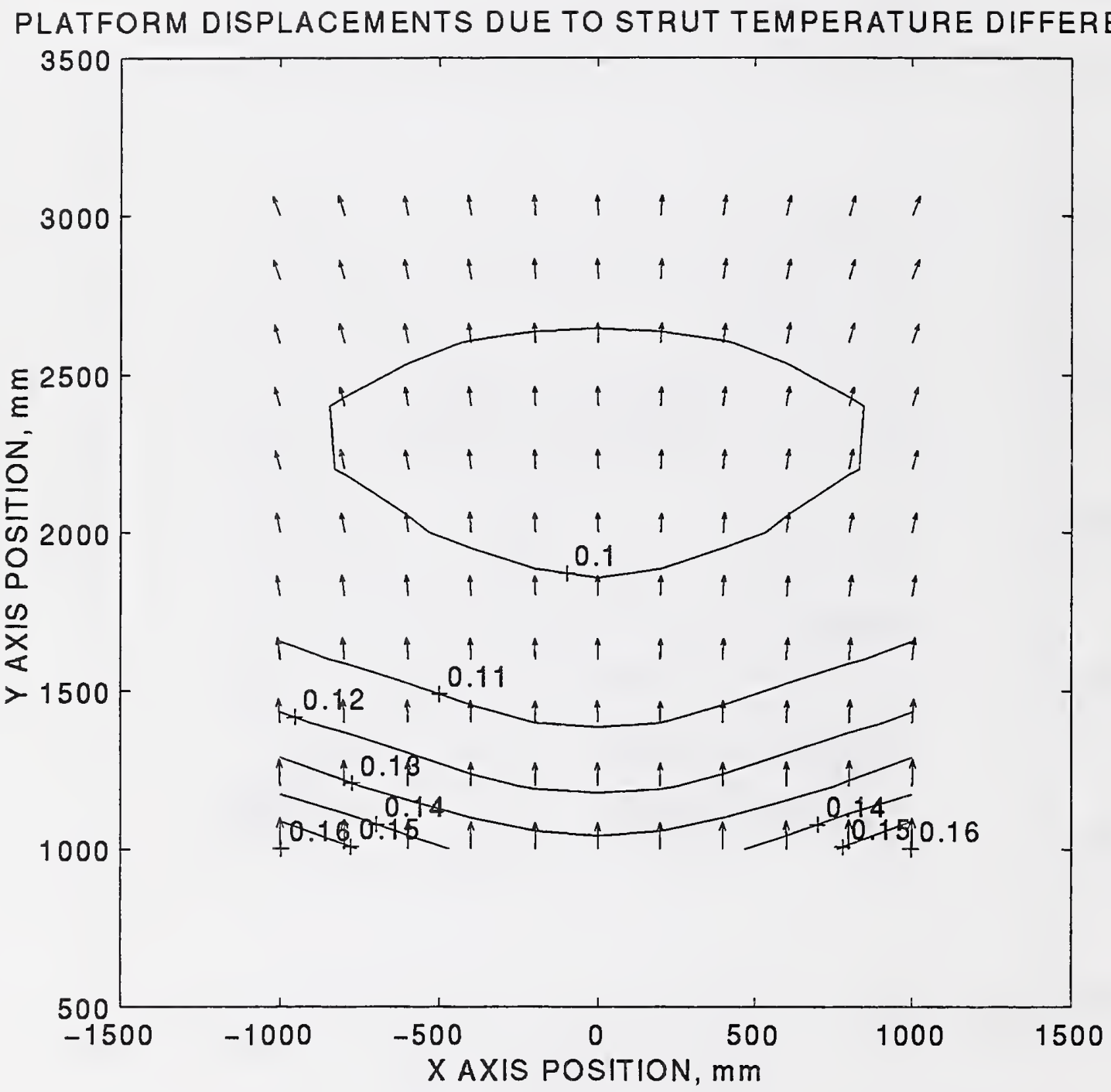

Figure 13a. Example 2: Displacement Vector Field; Displacements due to Leg Temperature Change 


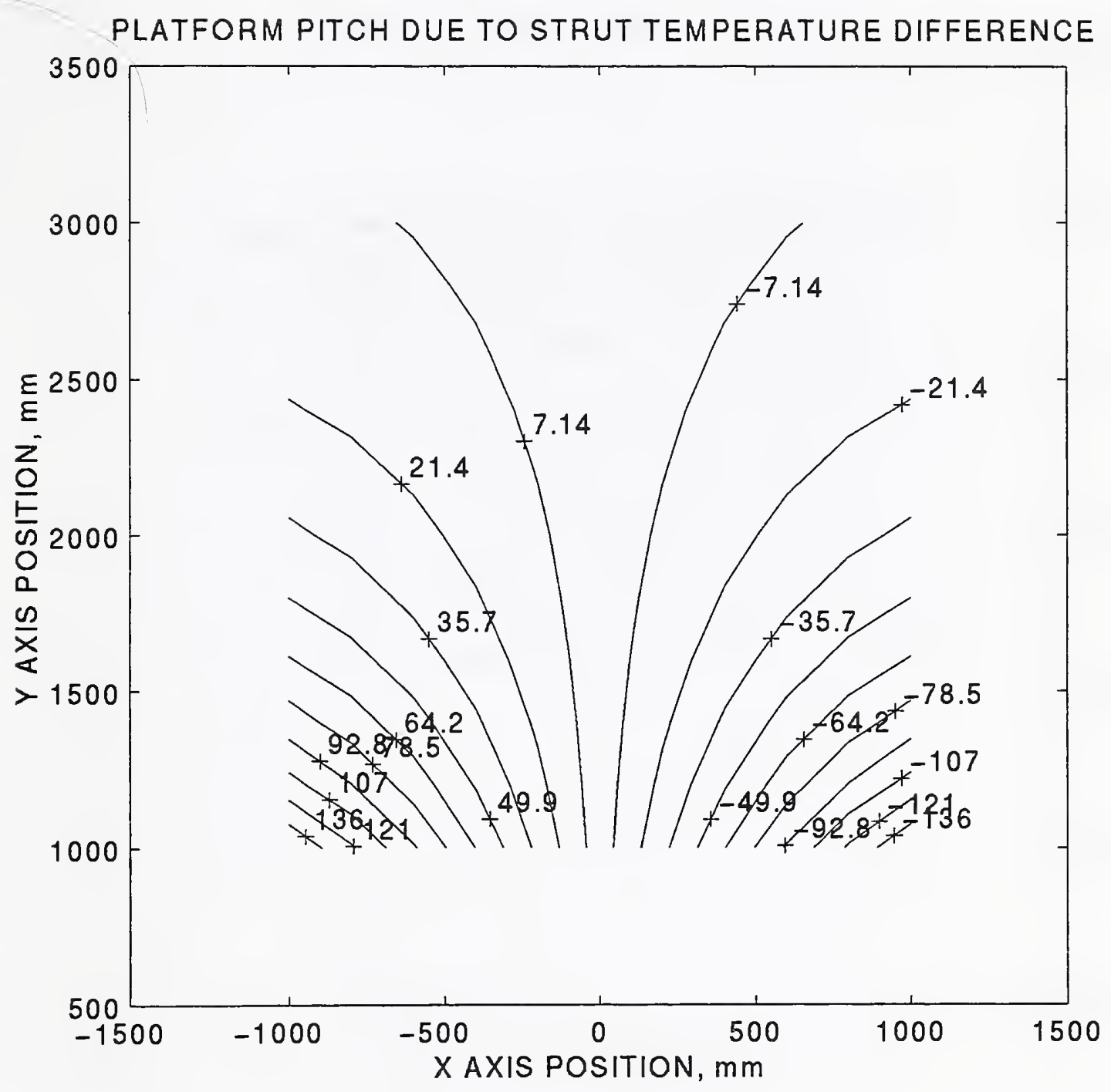

Figure 13b. Example 2: Platform Pitch Contour P1ot; Pitch due to Leg Temperature Change 


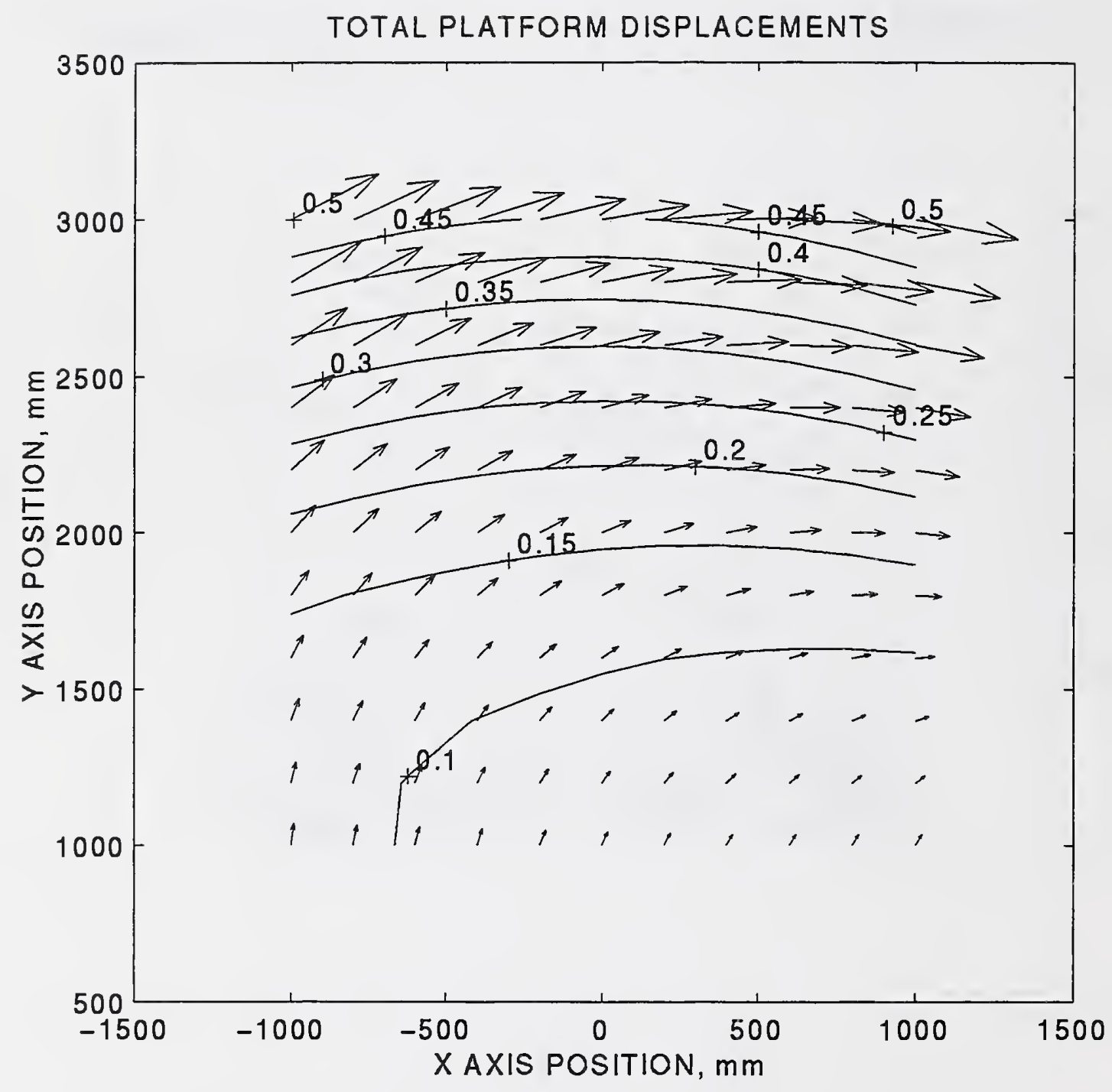

Figure 14a. Example 2: Displacement Vector Field; Total Displacements 


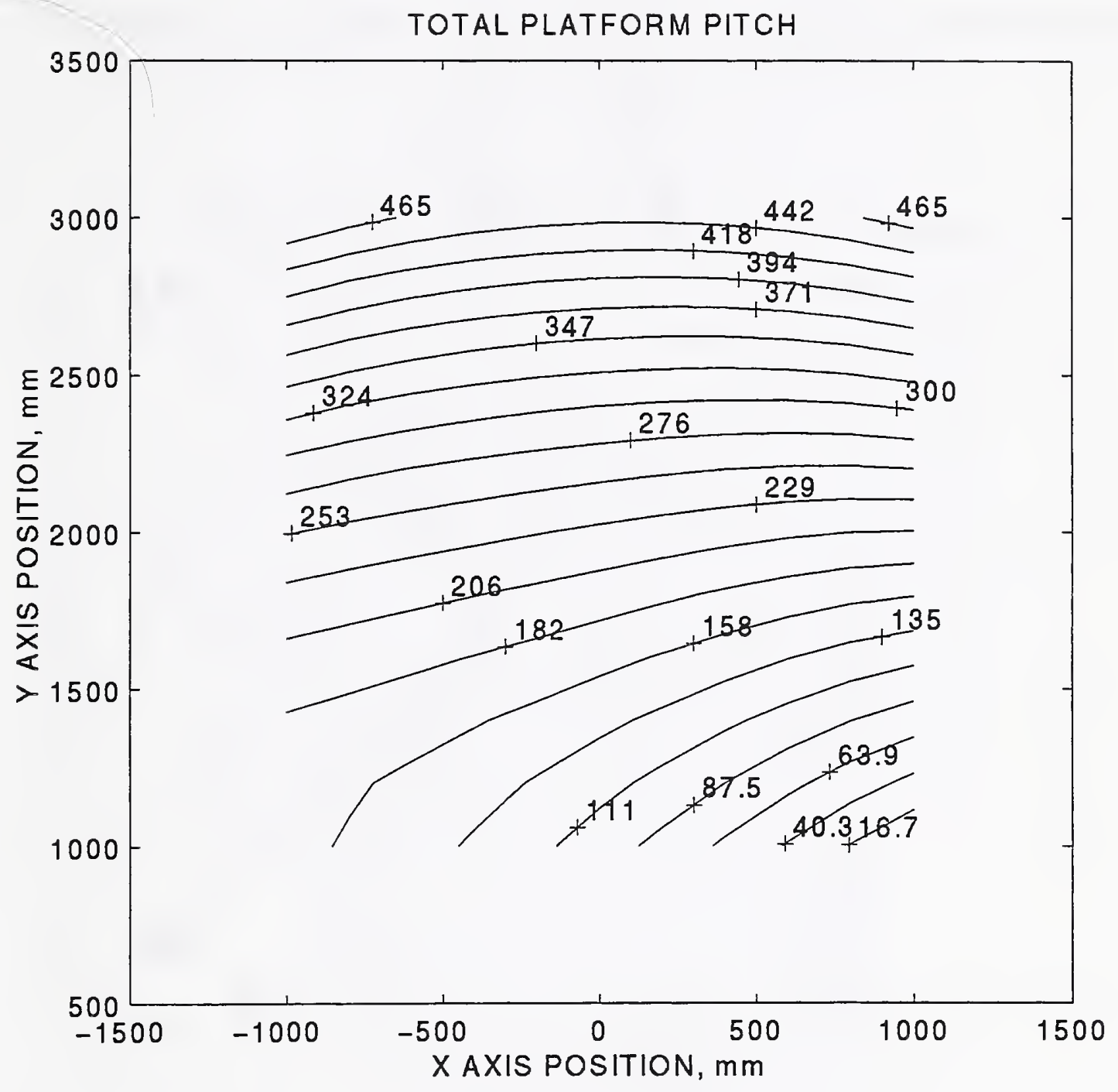

Figure 14b. Example 2: Platform Pitch Contour Plot; Total Platform Pitch 


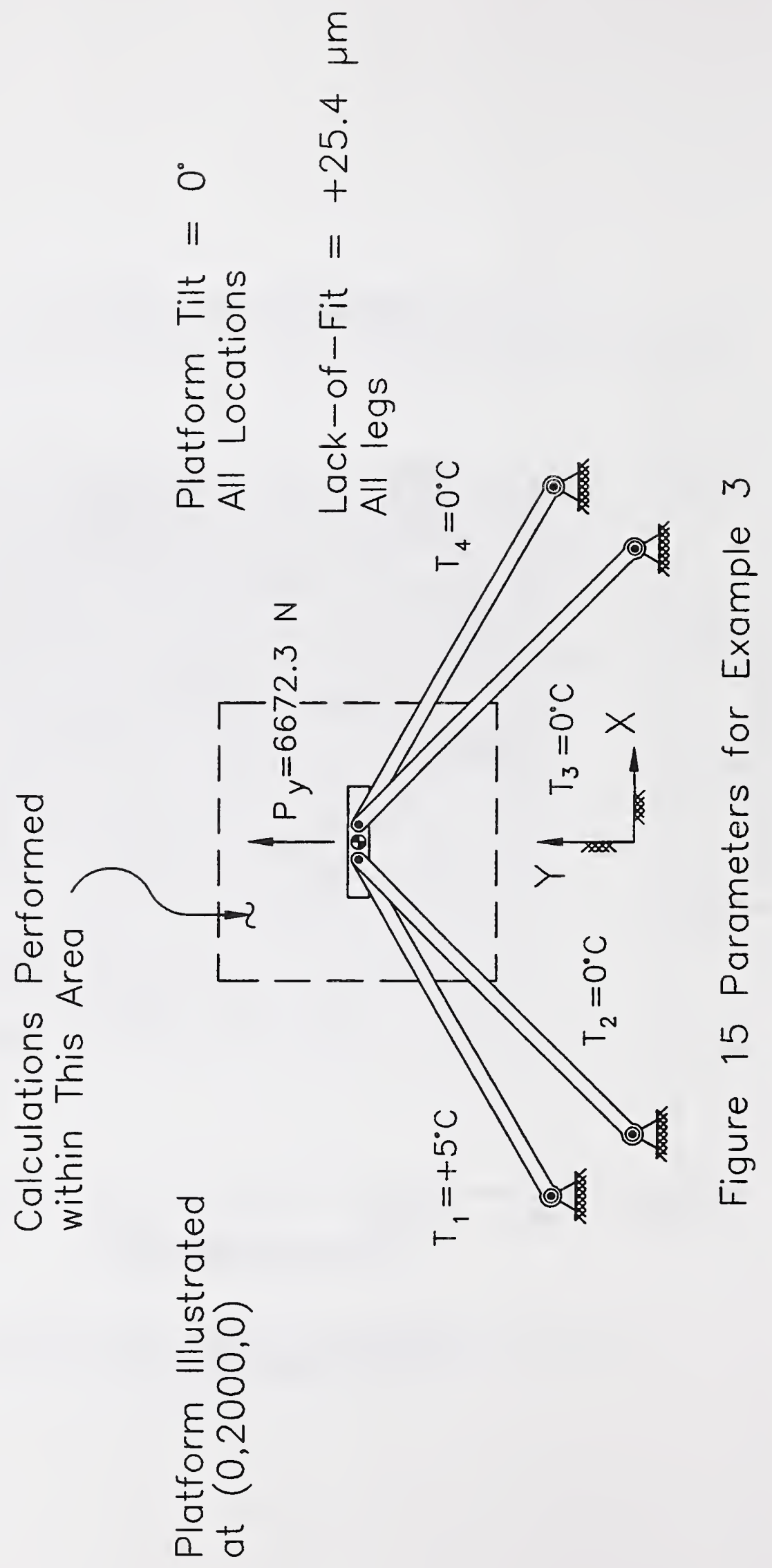




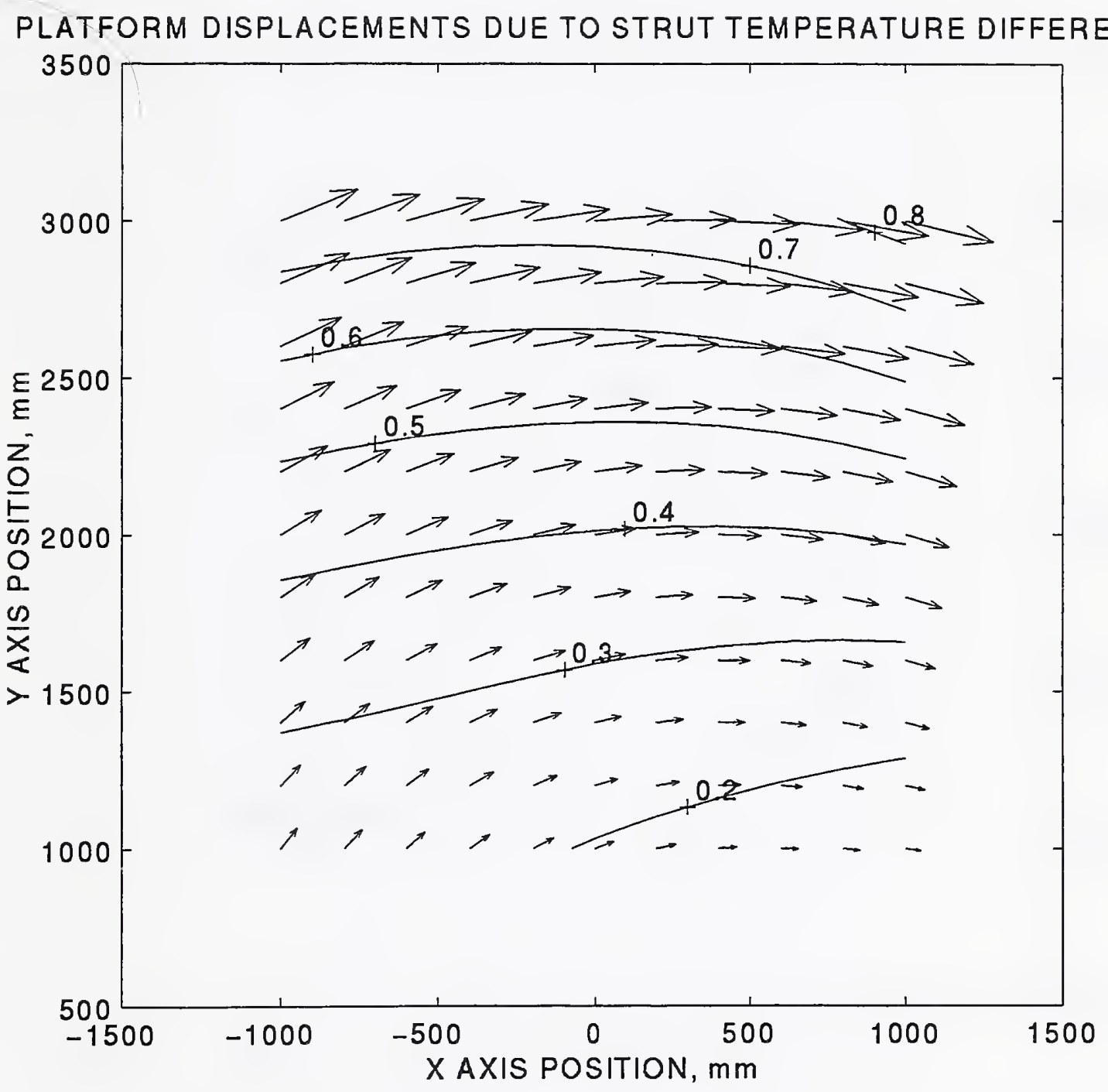

Figure 16a. Example 3: Displacement Vector Field; Displacements due to Leg Temperature Change 


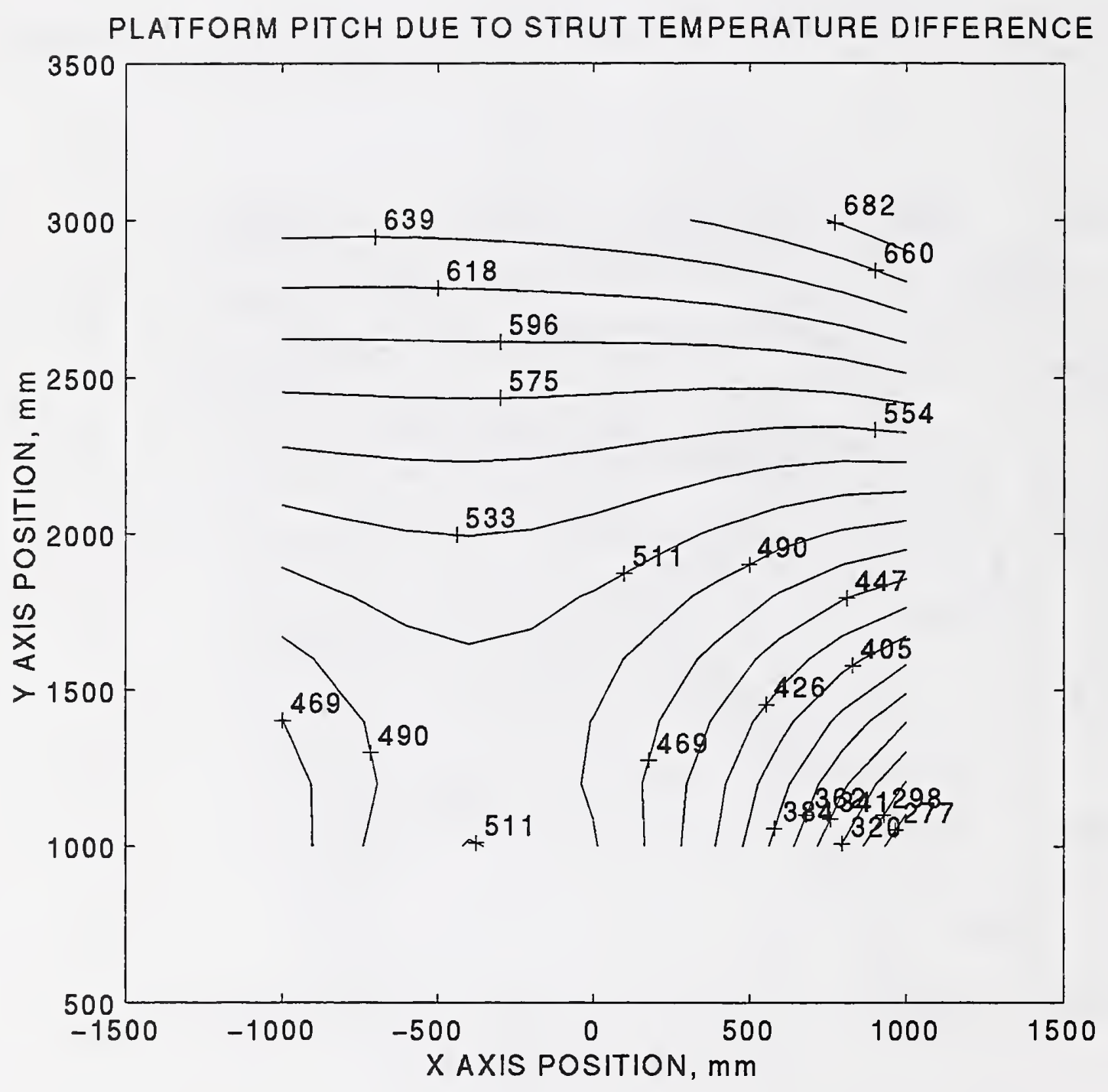

Figure 16b. Example 3: Platform Pitch Contour Plot; Pitch due to Leg Temperature Change 


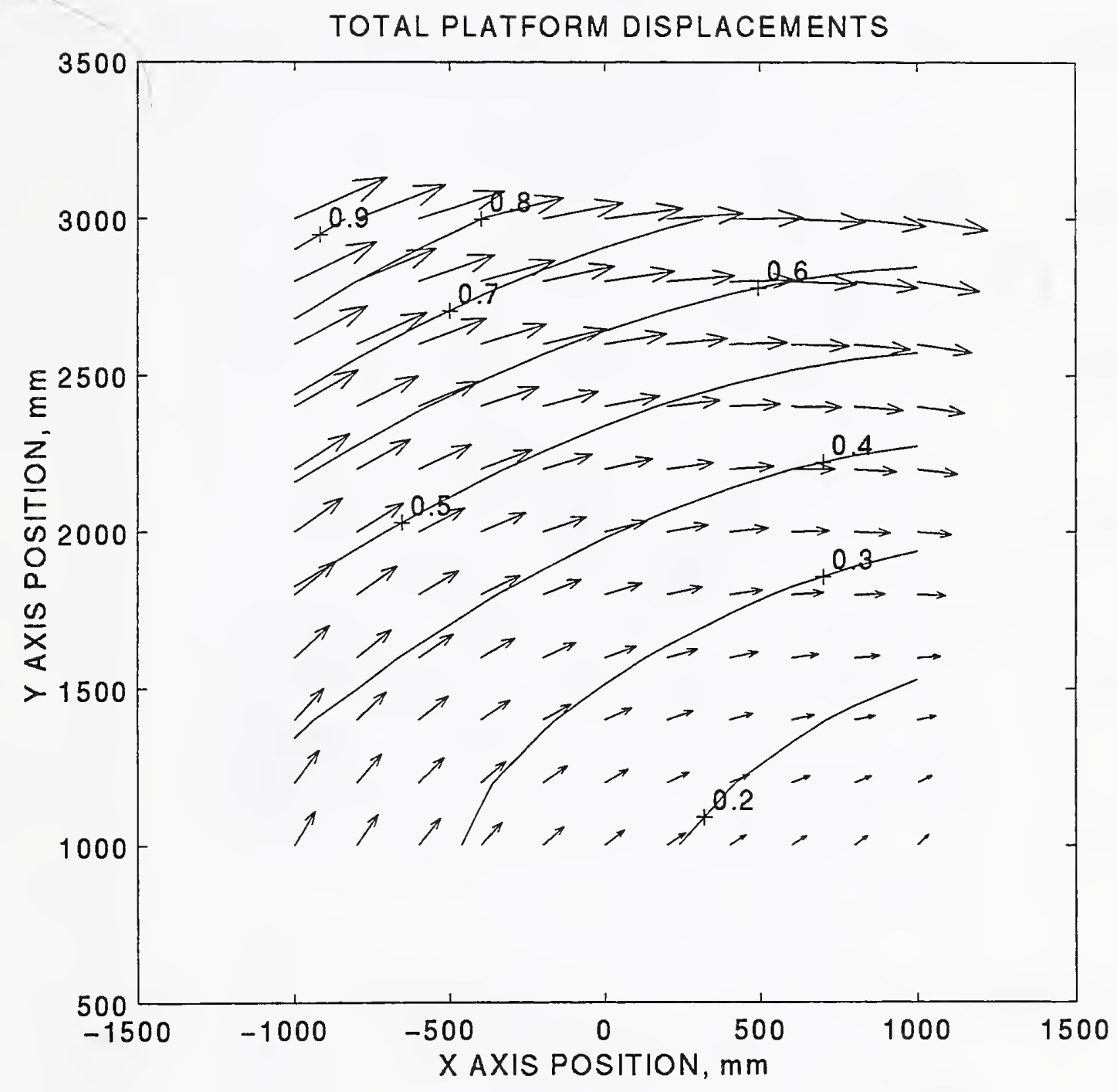

Figure 17a. Example 3: Displacement Vector Field;

Total Displacements 


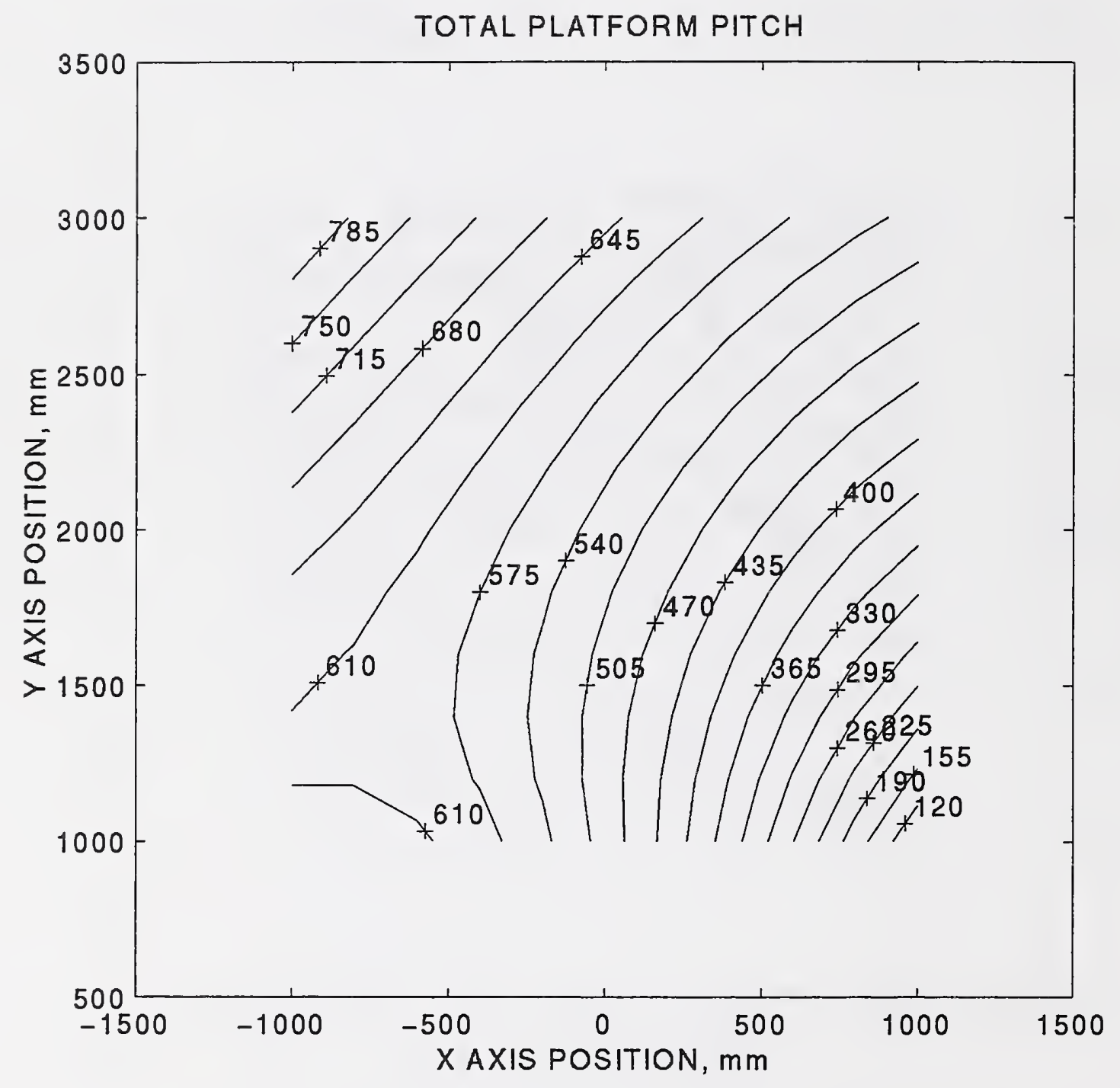

Figure 17b. Example 3: Platform Pitch Contour Plot; Total Platform Pitch 


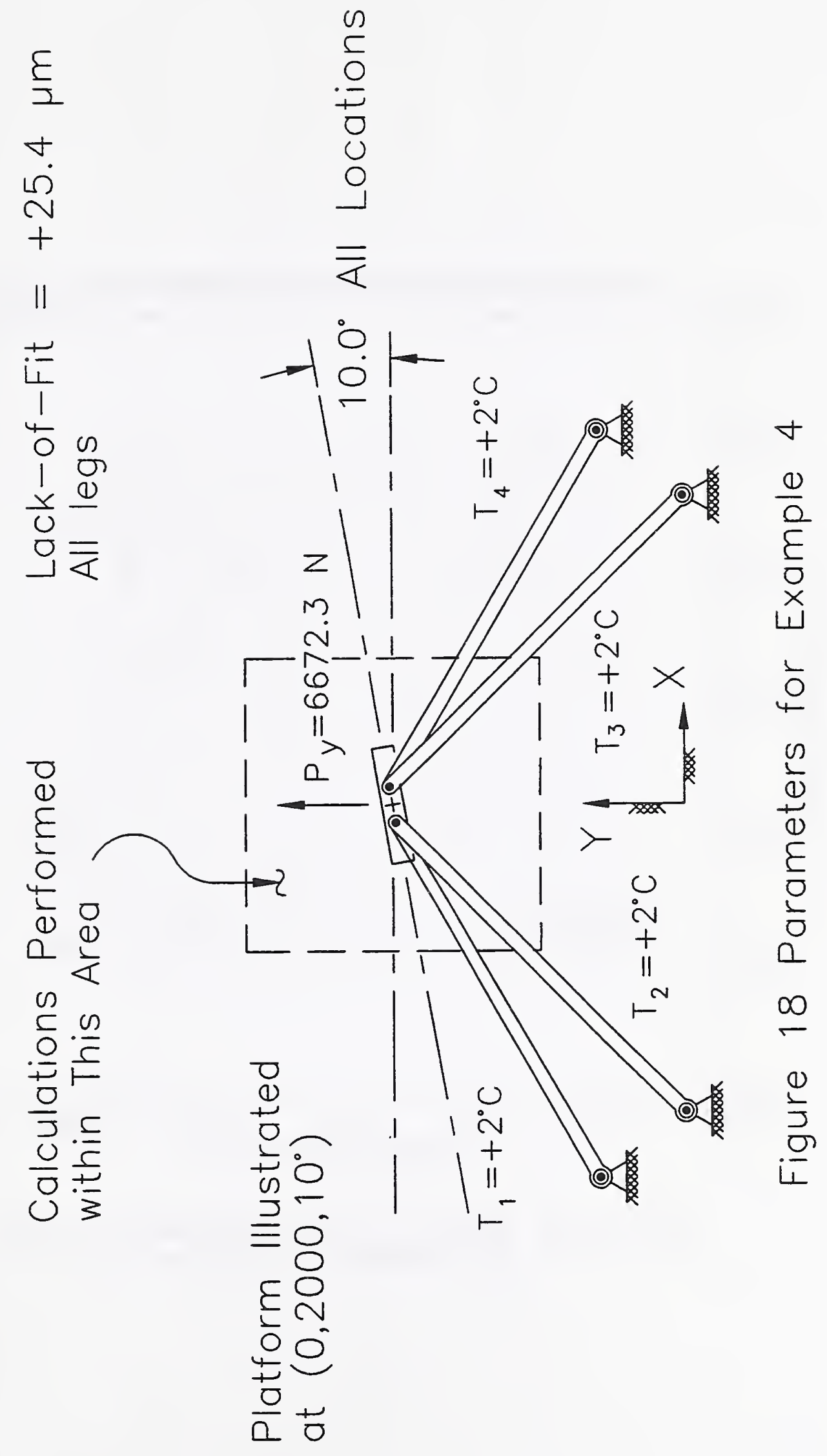




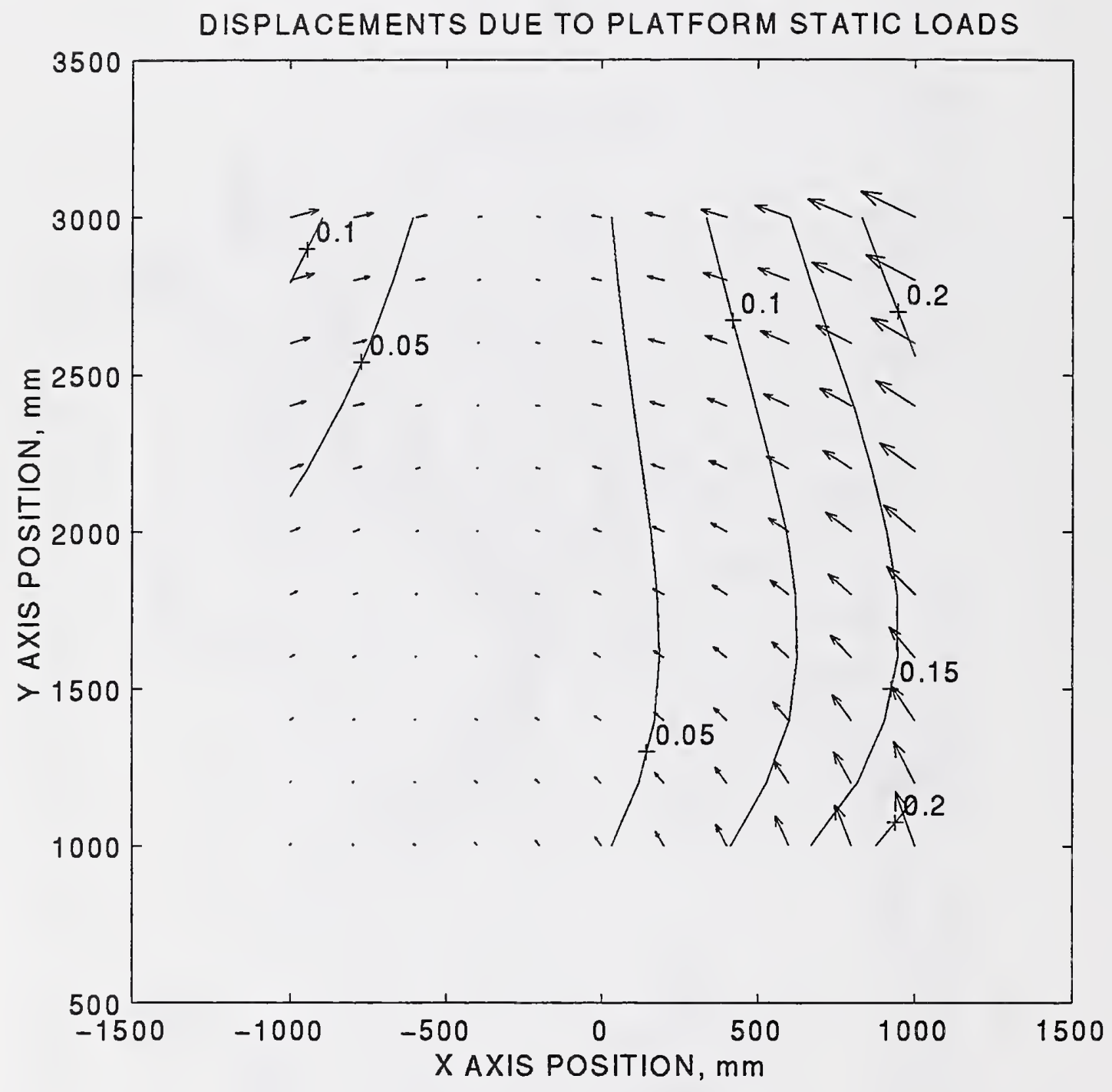

Figure 19a. Example 4: Displacement Vector Field; Displacements due to Static Loads 


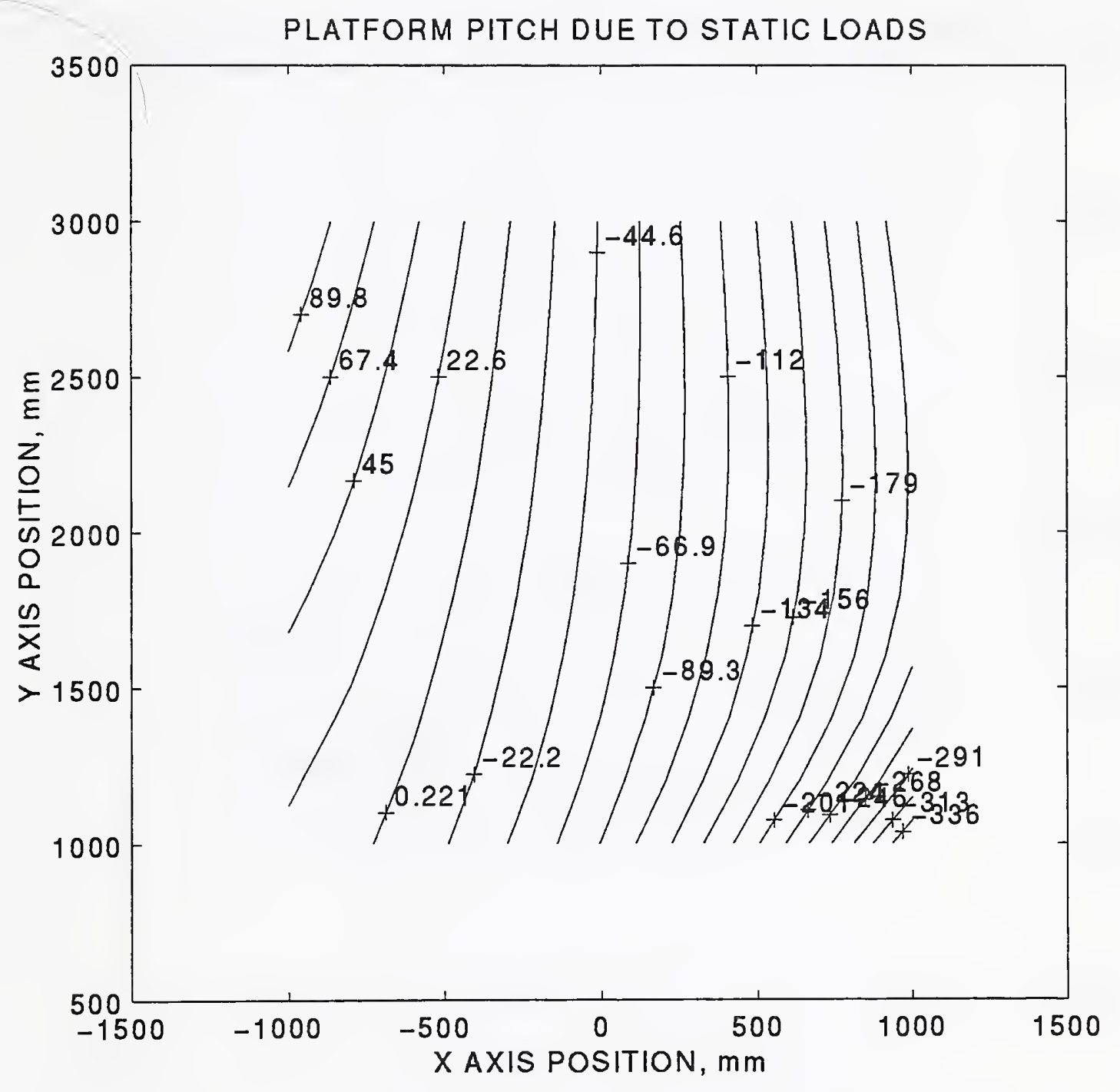

Figure 19b. Example 4: Platform Pitch Contour Plot;

Pitch due to Static Loads 


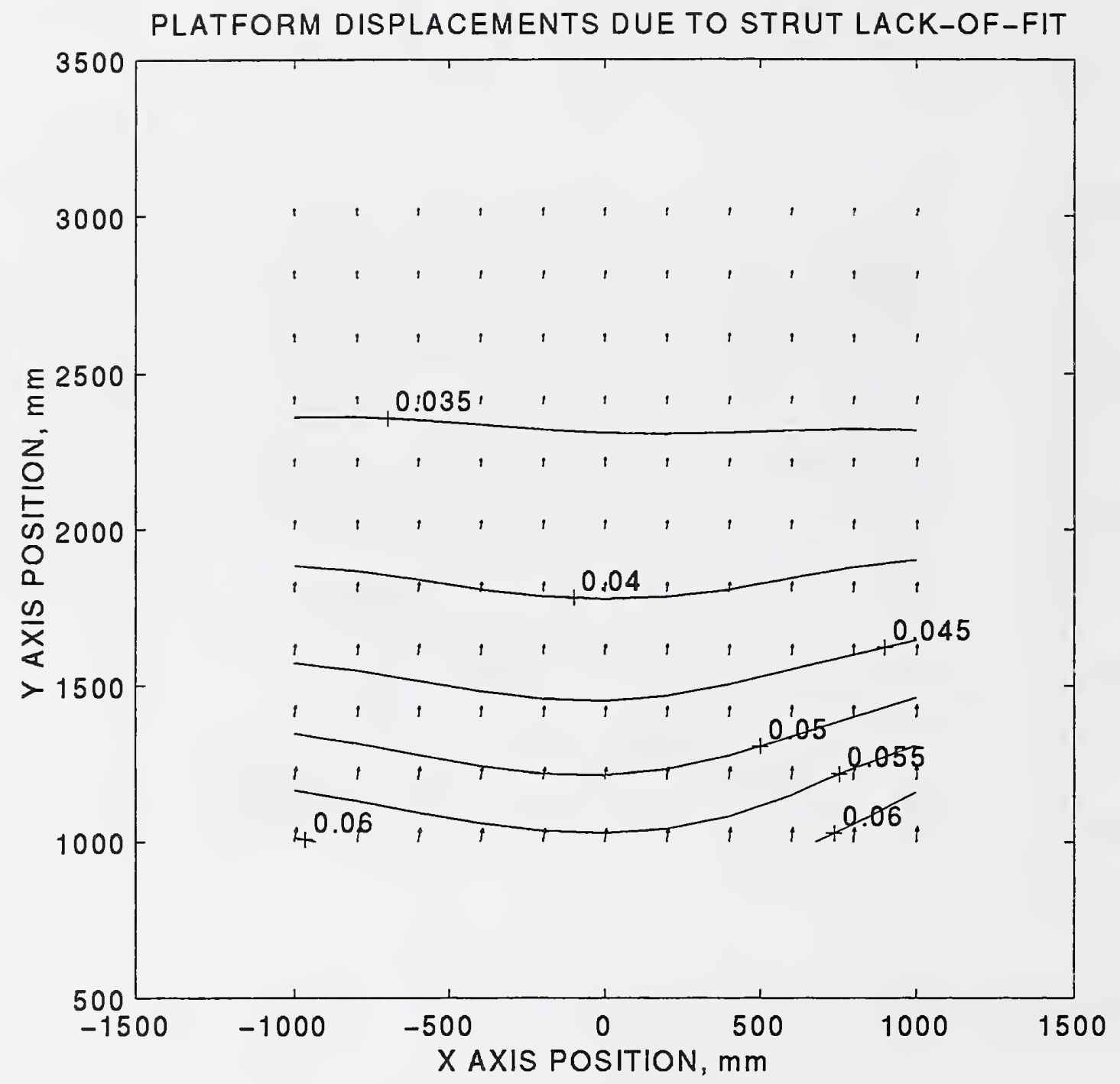

Figure 20a. Example 4: Displacement Vector Field; Displacements due to Leg Lack-of-Fit 


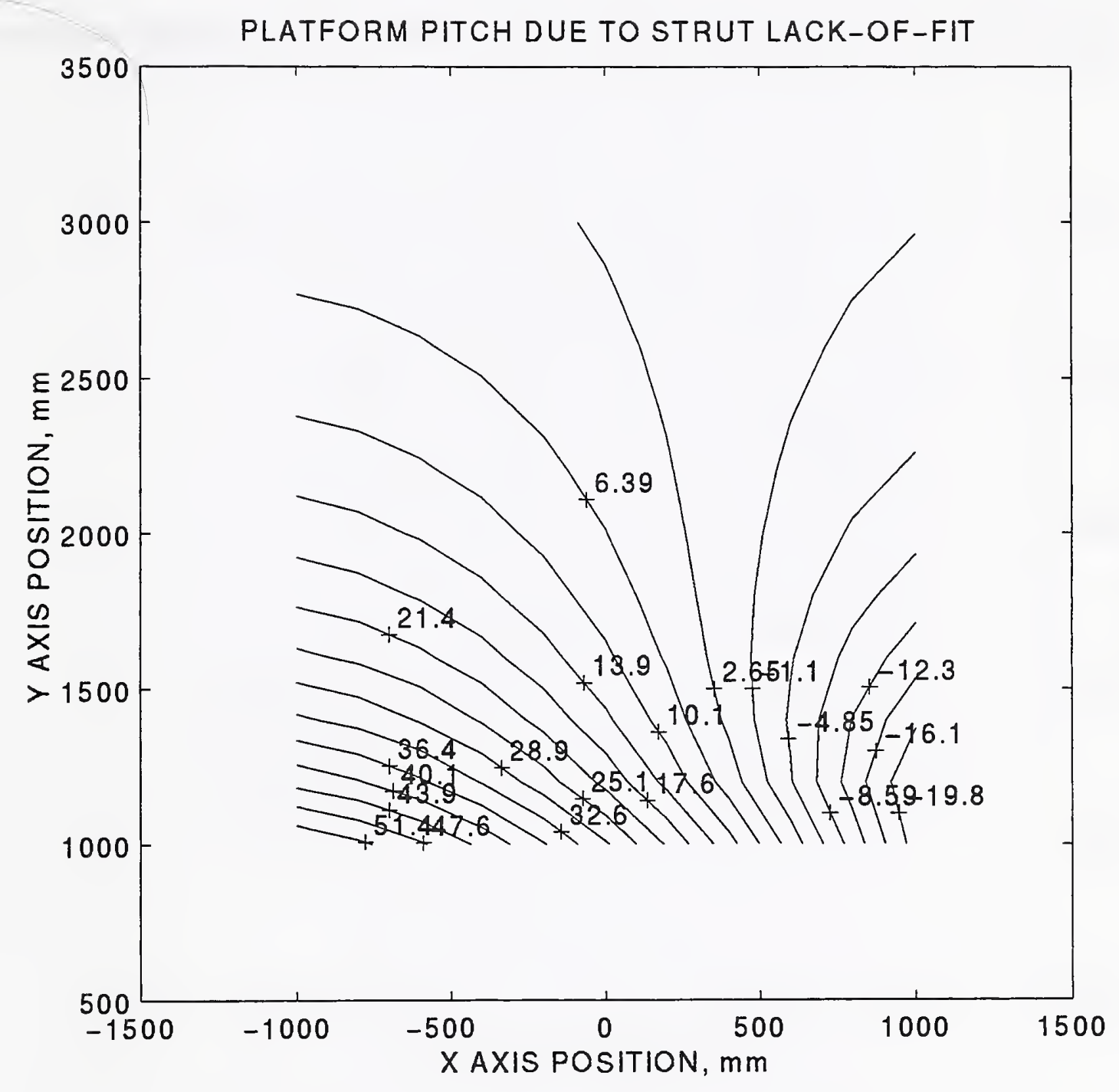

Figure 20b. Example 4: Platform Pitch Contour Plot; Pitch due to Leg Lack-of-Fit 


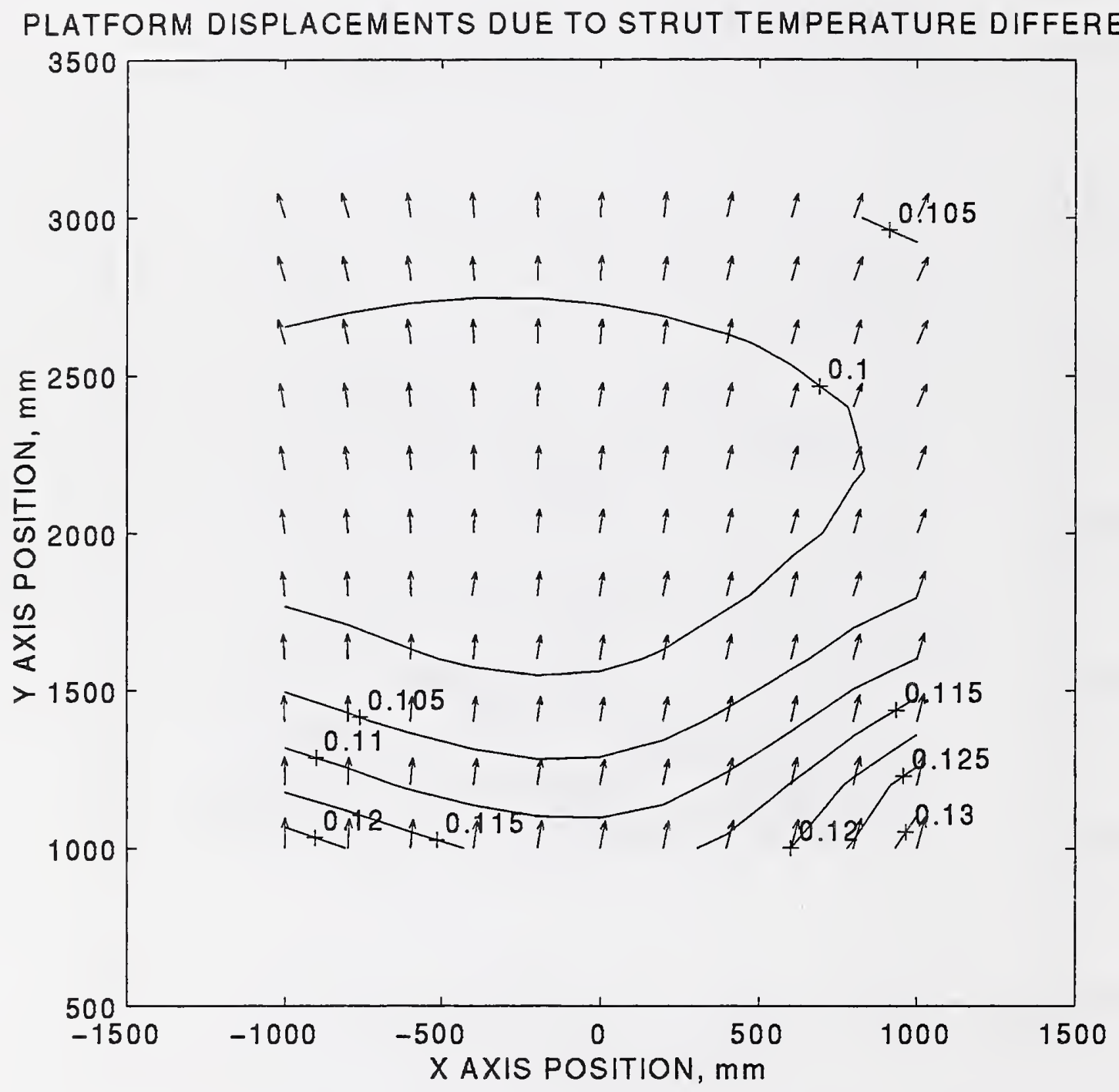

Figure 21a. Example 4: Displacement Vector Field; Displacements due to Leg Temperature Change 


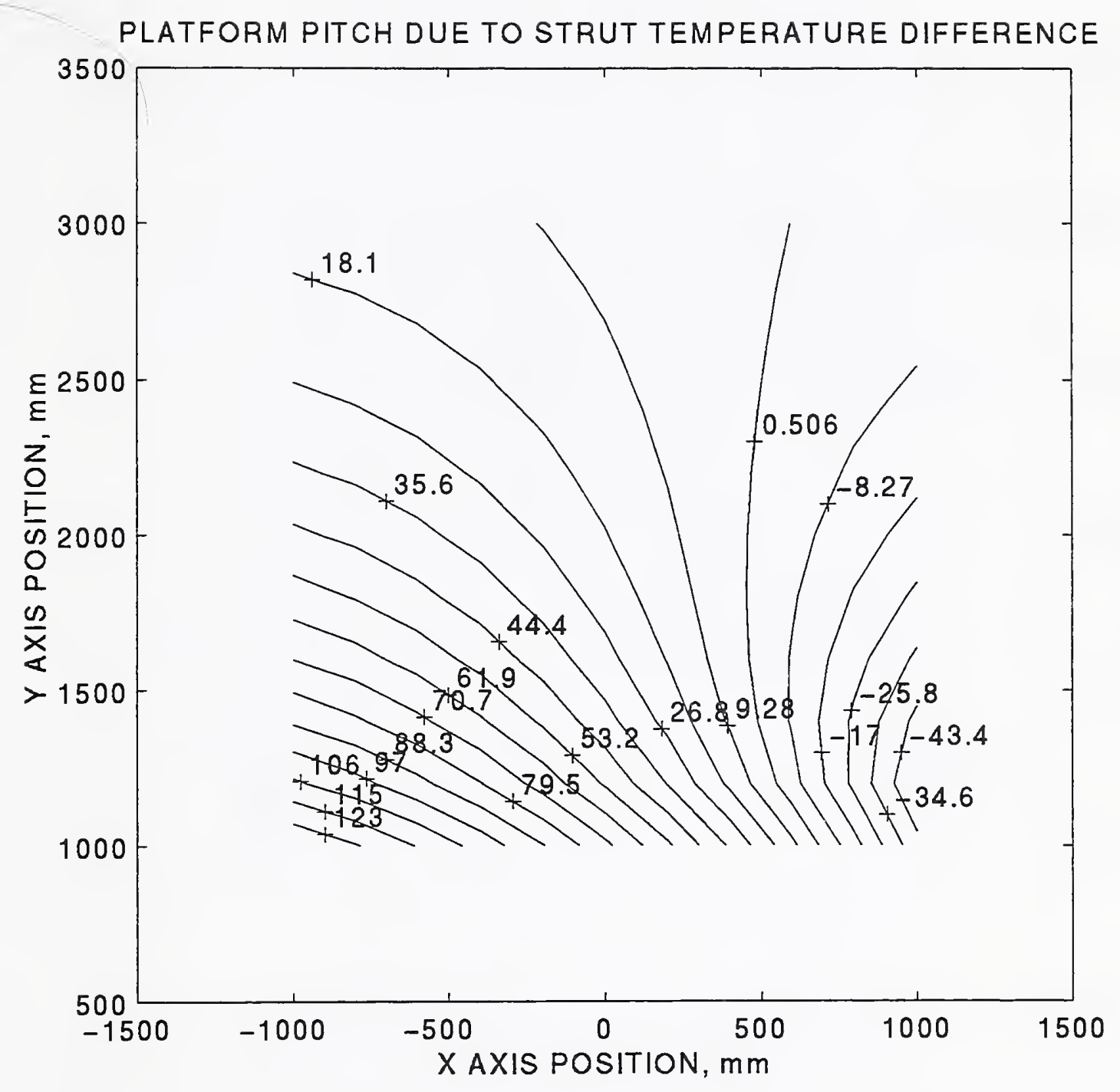

Figure 21b. Example 4: Platform Pitch Contour Plot;

Pitch due to Leg Temperature Change 
TOTAL PLATFORM DISPLACEMENTS

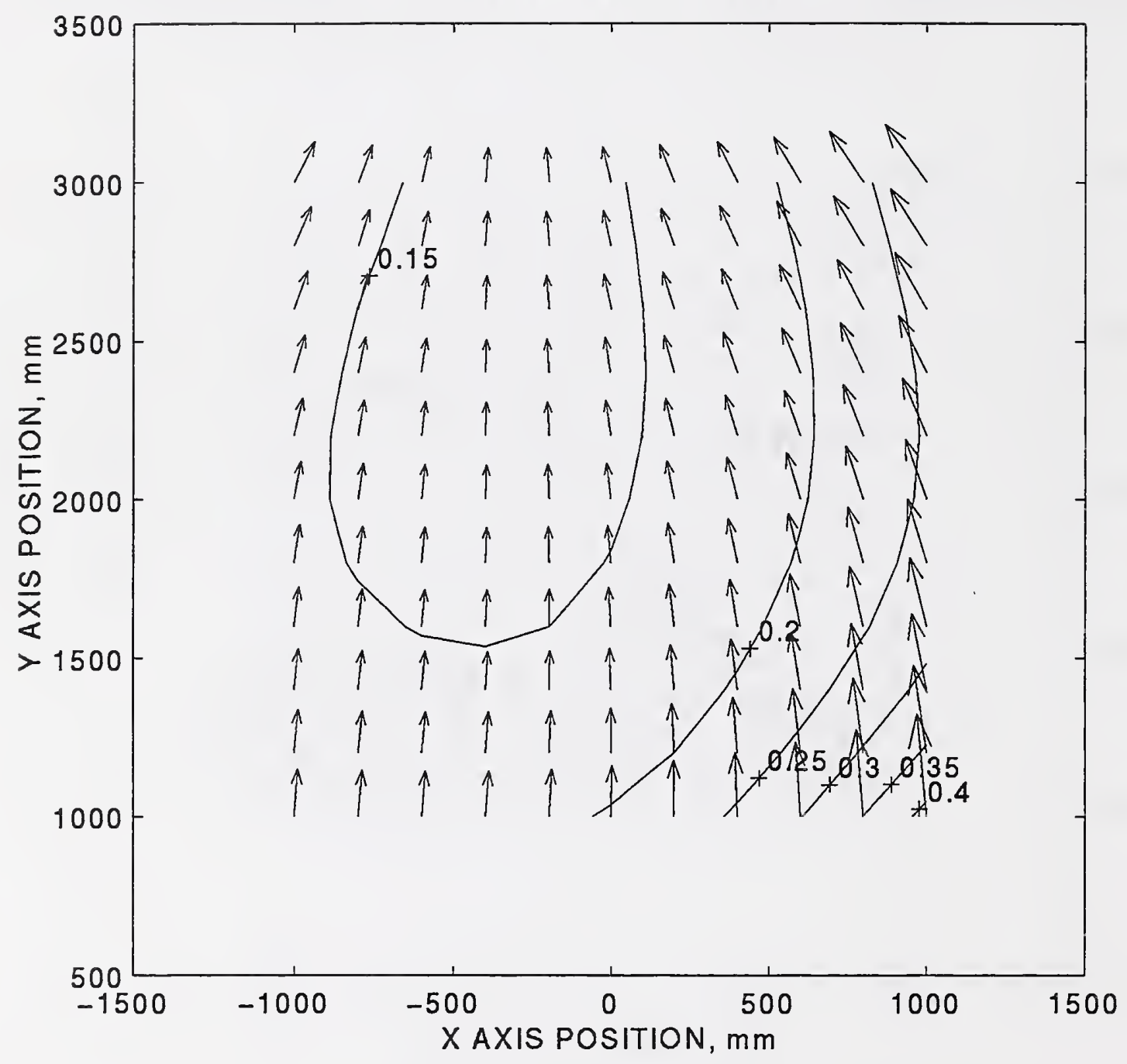

Figure 22a. Example 4: Displacement Vector Field; Total Displacements 


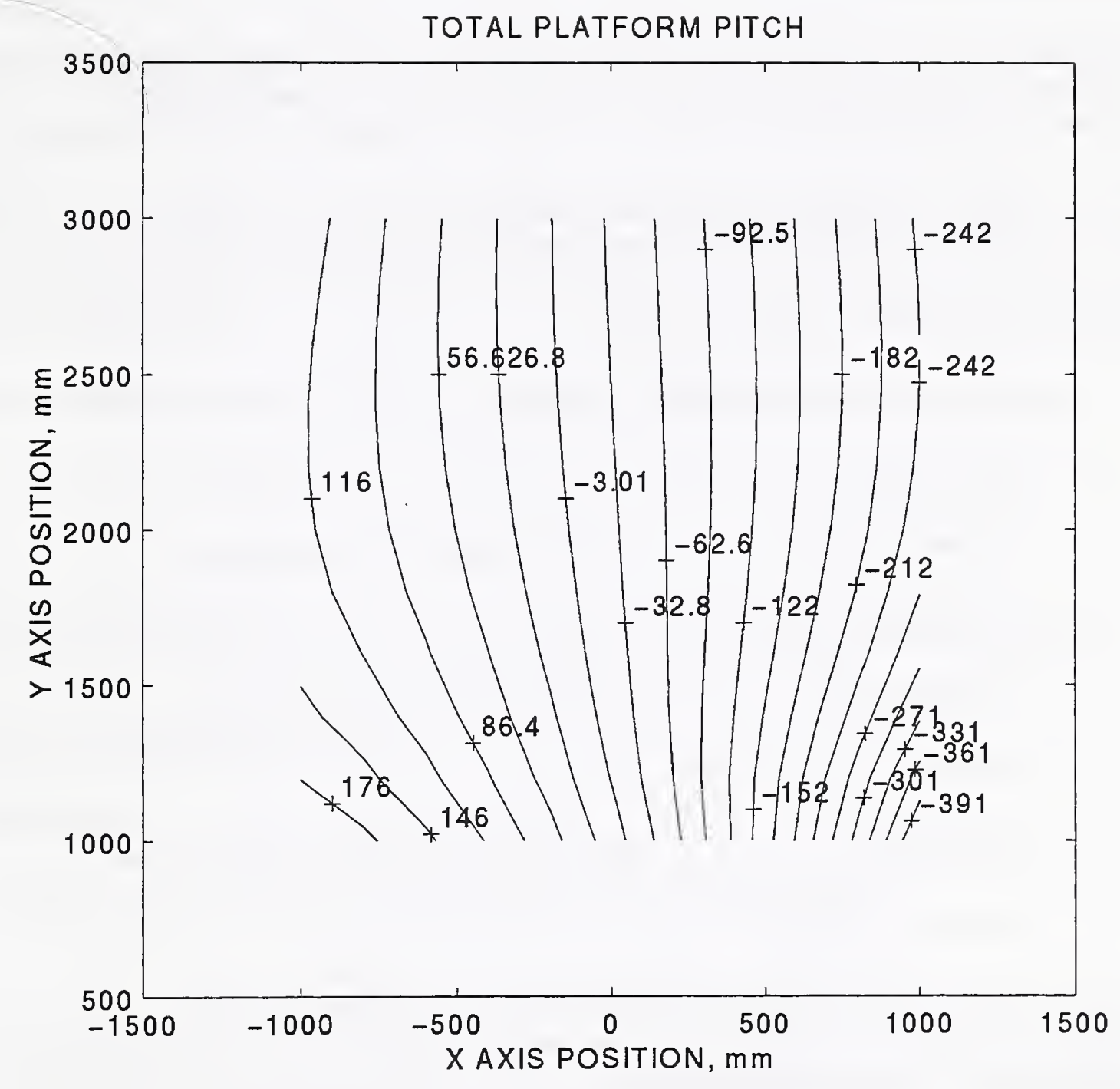

Figure 22b. Example 4: Platform Pitch Contour Plot; Tota1 Platform Pitch 


\section{Appendix: Analysis Details}

\section{Equilibrium Equations}

This appendix presents the derivation of the equilibrium equations for the structure. The derivation is an application of the principle of virtural work.

\section{Principle of Virtural Work}

For an elastic body subjected to loading, temperature changes and initial strains, the elastic body is in equilibrium for any virtural displacements $\delta \mathrm{u}, \delta \mathrm{v}, \delta \mathrm{w}$ from a compatible state of deformation provided that $\delta \mathrm{W}=\delta \mathrm{U}_{\mathrm{i}}$

where $\quad \delta \mathrm{W}$ is the increment of work for $(\delta \mathrm{u}, \delta \mathrm{v}, \delta \mathrm{w})$

$\delta \mathrm{U}_{\mathrm{i}} \quad$ is the increment of (internal) strain energy for $(\delta \mathrm{u}, \delta \mathrm{v}, \delta \mathrm{w})$

More explictly (bold type face denotes a vector)

$$
\begin{aligned}
& \delta W=\int_{\mathrm{V}} \sigma \delta \gamma \mathrm{dV}=\int_{\mathrm{V}} \omega \delta \mathrm{udV}+\int_{\mathrm{s}} \phi \delta \mathrm{udS} \\
& \delta \mathrm{U}_{\mathrm{i}}=\int_{\mathrm{V}} \sigma \delta \in \mathrm{dV} \\
& \sigma \text { : elastic stresses } \quad \int_{\mathrm{V}}() \mathrm{dV} \text { integration over volume } \\
& \gamma=\epsilon+\eta \text { : total strain } \\
& \epsilon \text { : elastic strains } \quad \int_{\mathrm{S}}() \mathrm{dS} \text { integration over surface area } \\
& \eta \text { : initial strains } \\
& \omega \text { : body force } \\
& \phi: \text { surface tractions }
\end{aligned}
$$

We now develop the explicit expressions to utilize the principle of virtural work.

\section{Application of The Principal of Virtural Work}

\section{Ideal Geometry}

For the structure considered in the analysis, the internal elastic potential or strain energy is determined by the deformation of the legs supporting the platform. A position $(X, Y, \Theta)$ is specified for the reference point on the platform. This position along with the locations of the 
platform joint $\left(\mathrm{x}_{\mathrm{p}}, \mathrm{y}_{\mathrm{p}}\right)_{\mathrm{r}}$ and the base joint $\left(\mathrm{x}_{\mathrm{b}}, \mathrm{y}_{\mathrm{b}}\right)_{\mathrm{r}}$ of the $\mathrm{r}^{\text {th }}$ leg defines the ideal strut length, $\mathrm{l}_{\mathrm{r}}$, and the direction cosines, $\cos \varphi_{\mathrm{r}}$, of the leg relative to the global axis $\mathrm{X}$.

Explicitly, we have the relationships (see Figures 1 and 2 )

$$
\begin{aligned}
& 1_{r}^{2}=\left(x_{p}-x_{b}\right)_{r}^{2}+\left(y_{p}-y_{b}\right)_{r}^{2} \\
& \cos \varphi_{r}=\left(x_{p}-x_{b}\right)_{r} l_{r} \\
& \sin \varphi_{r}=\left(y_{p}-y_{b}\right)_{r} / l_{r} .
\end{aligned}
$$

\section{Platform and Leg Displacements}

Now, due to the platform loading, thermal strains and initial strains in the legs, the reference point on the platform undergoes small displacements $(u, v, \theta)$ in the $(X, Y, \Theta)$ directions. These small displacements of the rigid platform result in the small displacements $\left(u_{T}, v_{r}\right)$ of each leg joint on the platform.

The relationship between the leg joint displacements and the platform displacements is

$$
\begin{aligned}
& \mathrm{u}_{\mathrm{r}}=\mathrm{u}-\mathrm{x}_{\mathrm{pr}} \sin \Theta \cdot \theta \\
& \mathrm{v}_{\mathrm{r}}=\mathrm{v}+\mathrm{x}_{\mathrm{pr}} \cos \Theta \cdot \theta
\end{aligned}
$$

where it is assumed that $y_{p r}=0$ and that the leg base joints $\left(x_{b}, y_{b}\right)_{r}$ are attached to a rigid foundation.

\section{Strain and Stresses in $\mathrm{r}^{\text {th }}$ Leg}

\section{Total Strain}

For the $\mathrm{r}^{\text {th }}$ leg, the total strain in the leg is then given by the expression:

$$
\gamma_{\mathrm{r}}=\left(\mathrm{u}_{\mathrm{T}} \cos \varphi_{\mathrm{r}}+\mathrm{v}_{\mathrm{r}} \sin \varphi_{\mathrm{r}}\right) / 1_{\mathrm{r}}
$$

The expressions for the initial strains consider two physical causes: 1) incorrect leg length at structure assembly, and 2) leg extension due to temperature change. A more complete explaination of these terms follows:

\section{Lack-of-Fit Strains}

The leg length, $1_{r}$, is the perfect or design leg length of the $r^{\text {th }}$ leg. For the set of leg joints $\left(x_{b}, y_{b}\right)_{r}$ and $\left(x_{p}, y_{p}\right)_{r}$, the platform is perfectly located at the specified position $(X, Y, \Theta)$. If there are two 
or more leg joints on the platform and three or more non-colinear legs supporting the platform, then if any leg deviates from its perfect length, $l_{r}$, the platform will deform an amount $\left(u_{0}, v_{0}, \theta_{0}\right)$ due to the load system induced by "forcing" the leg to fit the ideal position of the platform. One may think of the platform as held in a rigid fixture at location $(X, Y, \Theta)$. Each leg is then assembled linking the base joint $\left(\mathrm{x}_{\mathrm{b}}, \mathrm{y}_{\mathrm{b}}\right)_{\mathrm{r}}$ to the platform joint $\left(\mathrm{x}_{\mathrm{p}}, \mathrm{y}_{\mathrm{p}}\right)_{\mathrm{r}}$. If the "lack-of-fit" is denoted by $\Delta \mathrm{l}_{\mathrm{r}}$, the leg must be strained (ie, "forced")

$$
\eta_{\text {or }}=\Delta \mathrm{l}_{\mathrm{r}} \mathrm{l}_{\mathrm{r}}
$$

to fit into the structural assembly. After all legs are assembled, the rigid fixture holding the platform is released and the initial strains $\eta_{\mathrm{or}}$ cause the platform to deform $\left(\mathrm{u}_{\mathrm{o}}, \mathrm{v}_{\mathrm{o}}, \theta_{\mathrm{o}}\right)$ from the ideal position $(X, Y, \Theta)$. The magnitude and sign of $\Delta \mathrm{l}_{\mathrm{r}}$ represents the total geometric manufacturing error of the leg.

\section{Thermal Strains}

As mentioned above, $\mathrm{l}_{\mathrm{r}}$ is the perfect or design length of the leg and $\Delta \mathrm{l}_{\mathrm{r}}$ is the total geometric manufacturing error of the leg. The magnitude of $\mathrm{l}_{\mathrm{r}}+\Delta \mathrm{l}_{\mathrm{r}}$ is determined at some temperature which we assume is the same for all legs (ie, the $\Delta \mathrm{l}_{\mathrm{r}}$ are all referenced to the same temperature). Now, suppose that the assembled structure is exposed to non-uniform heating such that a leg experiences a temperature change, $T_{\mathrm{r}}$, relative to the reference temperature at manufacture. Then, the leg experiences a thermal strain

$$
\eta_{T_{r}}=\alpha_{\mathrm{r}} T_{\mathrm{r}}
$$

where $\alpha_{\mathrm{r}}$ is the coefficient of thermal expension and $T_{\mathrm{r}}$ is the temperature change.

We note that if $\mathrm{T}_{\mathrm{r}}(\mathrm{s})$ is a function of axial position, $\mathrm{s}$, along the leg then the "thermal load" induced in the leg is proportional to the integral

$$
\int_{0}^{l_{r}} \eta_{T r}(s) d s=\alpha_{r} \int_{0}^{l_{r}} T_{r}(s) d s .
$$

If the temperature change is constant or varies linearly with position along the leg, then one may express the temperature change as a constant or average temperature over the length of the leg. The explicit expression for the "thermal loading" resulting from the temperature change is given below. These thermal loads cause the platform to deform $\left(\mathrm{u}_{\mathrm{T}}, \mathrm{v}_{\mathrm{T}}, \theta_{\mathrm{T}}\right)$ from the ideal position $(\mathrm{X}, \mathrm{Y}, \Theta)$.

\section{$\underline{\text { Elastic Strains }}$}


To evaluate the expression for the strain energy of the structure it is necessary to express the elastic strains in terms of the platform displacements and the initial strains of each leg.

For the $\mathrm{r}^{\text {th }}$ leg the expression are

$$
\epsilon_{\mathrm{r}}=\gamma_{\mathrm{r}}-\left(\eta_{\mathrm{or}}+\eta_{\mathrm{Tr}}\right)
$$

or

$$
\epsilon_{\mathrm{r}}=\left[u_{\mathrm{T}} \cos \varphi_{\mathrm{r}}+\mathrm{v}_{\mathrm{r}} \sin \varphi_{\mathrm{r}}\right] / \mathrm{l}_{\mathrm{r}}-\left(\Delta \mathrm{l}_{\mathrm{r}} \mathrm{l}_{\mathrm{r}}+\alpha_{\mathrm{r}} \mathrm{T}_{\mathrm{r}}\right)
$$

\section{$\underline{\text { Stresses }}$}

Each leg is assumed to be an ideal axially loaded structural member. Assuming a constant cross sectional area of the leg, $A_{r}$, and a constant value of Young's modulus, $E_{r}$, the expression for the stress in the $\mathrm{r}^{\text {th }}$ leg is:

$$
\sigma_{\mathrm{r}}=\mathrm{E}_{\mathrm{r}} \epsilon_{\mathrm{r}}=\mathrm{E}_{\mathrm{r}}\left[\mathrm{u}_{\mathrm{r}} \cos \varphi_{\mathrm{r}}+\mathrm{v}_{\mathrm{r}} \sin \varphi_{\mathrm{r}}\right] / \mathrm{l}_{\mathrm{r}}-\mathrm{E}_{\mathrm{r}} \Delta \mathrm{l}_{\mathrm{r}} \mathrm{l}_{\mathrm{r}}-\alpha_{\mathrm{r}} \mathrm{E}_{\mathrm{r}} \mathrm{T}_{\mathrm{r}}
$$

where the displacement $u_{\mathrm{T}}$ and $\mathrm{v}_{\mathrm{r}}$ are expressed above in terms of the platform displacements $(\mathrm{u}, \mathrm{v}, \theta)$.

\section{Strain Energy Expression}

To evaluate the increment of the strain energy, the platform is given the virtual displacements $(\delta \mathrm{u}, \delta \mathrm{v}, \delta \theta)$ while the stresses are held constant. The stresses arise from loading the platform $\left(\mathrm{P}_{\mathrm{X}}, \mathrm{P}_{\mathrm{Y}}, \mathrm{M}\right)$ in the $(\mathrm{X}, \mathrm{Y}, \Theta)$ directions and the initial strains due to lack-of-fit and temperature change. Since during the virtural displacements $(\delta u, \delta v, \delta \theta)$ the initial strains are not varied the expression for the increment in the strain energy for the $\mathrm{r}^{\text {th }}$ leg is

$$
\delta \mathrm{U}_{\mathrm{ir}}=\int_{\mathrm{V}_{\mathrm{r}}} \sigma_{\mathrm{r}} \delta \epsilon_{\mathrm{r}} \mathrm{dV}=\int_{\mathrm{V}_{\mathrm{r}}} \sigma_{\mathrm{r}} \delta \gamma_{\mathrm{r}} \mathrm{dV}
$$

where $\iint_{\mathrm{V}_{\mathrm{r}}}(\ldots) \mathrm{dV}$ denotes the volume integral over the volume of the $\mathrm{r}^{\text {th }}$ leg.

The relevant expressions for evaluating the integral are

$$
\delta \gamma_{\mathrm{r}}=\delta \epsilon_{\mathrm{r}}=\left[\delta \mathrm{u} \cdot \cos \varphi_{\mathrm{r}}+\delta \mathrm{v} \cdot \sin \varphi_{\mathrm{r}}-\mathrm{x}_{\mathrm{pr}} \sin \left(\Theta-\varphi_{\mathrm{r}}\right) \delta \theta\right] / 1_{\mathrm{r}}
$$

$\sigma_{\mathrm{r}}$ is expressed above

and $\int_{V r}(\ldots) d V=A_{r} \int_{0}^{l_{r}}(\ldots) d s$. ( $s$ is the axial coordinate) 
Substituting the above expressions into the volume integral, performing the integration over the volume of the $\mathrm{r}^{\text {th }} \mathrm{leg}$, and summing over all legs one obtains:

$$
\begin{gathered}
\delta U_{i}=\sum_{r} \delta U_{i r} \\
\delta U_{i}=\sum_{r}\left[\kappa_{r} \cos ^{2} \varphi_{r} \cdot u+\kappa_{r} \sin \varphi_{r} \cos \varphi_{r} v+\kappa_{r} x_{p r} \cos \varphi_{r} \sin \left(\varphi_{r}-\Theta\right) \theta+\right. \\
\left.\quad-\kappa_{r} \cos \varphi_{r} \Delta l_{r}-\alpha_{r} \kappa_{r} \int_{o}^{l_{r}} T_{r}(s) d s \cdot \cos \varphi_{r}\right] \delta u \\
+\left[\kappa_{r} \sin \varphi_{r} \cos \varphi_{r} u+\kappa_{r} \sin ^{2} \varphi_{r} v+\kappa_{r} x_{p r} \sin \varphi_{r} \sin \left(\varphi_{r}-\Theta\right) \theta+\right. \\
\left.\quad-\kappa_{r} \sin \varphi_{r} \Delta l_{r}-\alpha_{r} \kappa_{r} \int_{o}^{l} T_{r}(s) d s \cdot \sin \varphi_{r}\right] \delta v \\
+\left[\kappa_{r} x_{p r} \cos \varphi_{r} \sin \left(\varphi_{r}-\Theta\right) u+\kappa_{r} x_{p r} \sin \varphi_{r} \sin \left(\varphi_{r}-\Theta\right) v+\right. \\
\quad+\kappa_{r} x_{p r}^{2} \sin { }^{2}\left(\varphi_{r}-\Theta\right)-\kappa_{r} x_{p r} \sin \left(\varphi_{r}-\Theta\right) \Delta l_{r} \\
\left.\quad-\alpha_{r} \kappa_{r} x_{p r} \int_{o}^{l_{r}} T_{r}(s) d s \sin \left(\varphi_{r}-\Theta\right)\right] \delta \theta \\
\text { where } \quad \kappa_{r}=A_{r} E_{r} / l_{r}
\end{gathered}
$$

In the above lengthly expression it is assumed that the temperature change $T_{r}(\mathrm{~s})$ varies along the length of the $\mathrm{r}^{\text {th }}$ leg.

\section{Virtural Work Expression}

The expression for the increment of virtural work, may be obtained from the surface integration given at the first of this appendix. However, it is more direct to give the expression for concentrated loading $\left(\mathrm{P}_{\mathrm{X}}, \mathrm{P}_{\mathrm{Y}}, \mathrm{M}\right)$ at the platform reference location as

$$
\delta \mathrm{W}=\mathrm{P}_{\mathrm{X}} \delta \mathrm{u}+\mathrm{P}_{\mathrm{Y}} \delta \mathrm{v}+\mathrm{M} \delta \theta \text {. }
$$

\section{Principle of Virtual Work Revisited}

The principle of virtual work is expressed as: 


$$
\delta U_{i}-\delta W=0
$$

Substituting the above expressions for $\delta \mathrm{U}_{\mathrm{i}}$ and $\delta \mathrm{W}$, we obtain

$$
\left[\sum_{r}(\ldots)-P_{X}\right] \delta u+\left[\sum_{r}(\ldots .)-P_{Y}\right] \delta v+\left[\sum_{r}(\ldots .)-M\right] \delta \theta=0
$$

where the terms $(\ldots$.$) are the respective lengthly expressions for the coefficients of \delta \mathrm{u}, \delta \mathrm{v}, \delta \mathrm{w}$ in the very lengthly expression for $\delta U_{i}$ given above. Since $\delta u, \delta v$, and $\delta \theta$ are arbitrary non-zero kinematically compatible virtural displacements, each expression given above in [...] must individually vanish. This gives the three static equilibrium equations.

\section{Equilibrium Equations}

In matrix format, the static equilibrium equations are expressed as

$$
\left[K_{i j}\right]\left\{\begin{array}{c}
u \\
v \\
\theta
\end{array}\right\}=\left\{\begin{array}{c}
P_{X} \\
P_{Y} \\
M
\end{array}\right\}+\left\{\begin{array}{l}
P_{\eta x} \\
P_{\eta \nu} \\
P_{\eta \theta}
\end{array}\right\}+\left\{\begin{array}{c}
P_{T x} \\
P_{T y} \\
P_{T \theta}
\end{array}\right\}
$$

where $\left[K_{i j}\right] \quad$ is the static stiffness matrix

$$
\begin{aligned}
& \left\{\begin{array}{l}
P_{X} \\
P_{Y} \\
M
\end{array}\right\} \quad \text { is the static platform loading } \\
& \left\{\begin{array}{l}
P_{\eta x} \\
P_{\eta y} \\
P_{\eta \theta}
\end{array}\right\} \quad \text { is the platform "loading" due to } \\
& \text { the lack-of-fit strains in the legs }
\end{aligned}
$$$$
\left\{\begin{array}{l}
P_{T x} \\
P_{T y} \\
P_{T \theta}
\end{array}\right\} \quad \begin{aligned}
& \text { is the platform "loading" due to } \\
& \text { the temperature changes in the legs }
\end{aligned}
$$

The explicit expressions for these terms are given below.

\section{$\underline{\text { Stiffness Matrix }}$}


The stiffness matrix is symmetric and arranged according to the platform displacement components $\mathrm{u}, \mathrm{v}, \theta$. The displacement $\mathrm{u}$ is a lateral platform movement. The displacement $\mathrm{v}$ is a vertical platform movement. The rotation $\theta$ is the direction of $\Theta$ or counterclockwise with respect to the $\mathrm{X}, \mathrm{Y}$ global coordinate system.

The terms in the stiffness matrix are:

- $\quad$ direct lateral stiffness

$$
K_{11}=\sum_{r} \kappa_{r} \cos ^{2} \varphi_{r}
$$

- $\quad$ lateral-vertical coupling stiffness

$$
K_{12}=\sum_{r} \kappa_{r} \sin \varphi_{r} \cos \varphi_{r}
$$

- lateral-rotational coupling stiffness

$$
K_{13}=\sum_{r} \kappa_{r} x_{p r} \cos \varphi_{r} \sin \left(\varphi_{r}-\Theta\right)
$$

- direct vertical stiffness

$$
K_{22}=\sum_{r} \kappa_{r} \sin ^{2} \varphi_{r}
$$

- vertical-rotation coupling stiffness

$$
K_{23}=\sum_{r} \kappa_{r} x_{p r} \sin \varphi_{r} \sin \left(\varphi_{r}-\Theta\right)
$$

- direct rotational stiffness

$$
K_{33}=\sum_{r} \kappa_{r} x_{p r}^{2} \sin ^{2}\left(\varphi_{r}-\Theta\right)
$$




$$
\text { where } \quad \begin{aligned}
& \sum_{r}(\ldots) \text { denotes summation over all the legs } \\
& \kappa_{r}=A_{r} E_{r} / l_{r} \\
& K_{j i}=K_{i j}
\end{aligned}
$$

\section{Platform Loading Due to Initial Strains}

The initial strains considered in this analysis are the lack-of-fit strains and the strains resulting from a temperature change for each leg.

Lack-of-Fit: The platform loading due to the lack-of-fit of the legs is given by the expression

$$
\left\{\begin{array}{l}
P_{\eta x} \\
P_{\eta \nu} \\
P_{\eta \theta}
\end{array}\right\}=\left\{\begin{array}{c}
\sum_{r} \kappa_{r} \cos \varphi_{r} \Delta l_{r} \\
\sum_{r} \kappa_{r} \sin \varphi_{r} \Delta l_{r} \\
\sum_{r} \kappa_{r} x_{p r} \sin \left(\varphi_{r}-\Theta\right) \Delta l_{r}
\end{array}\right\}
$$

where $\Delta \mathrm{l}_{\mathrm{r}}$ is the lack-of-fit of the $\mathrm{r}^{\text {th }}$ leg.

Temperature Change: The platform loading due to the temperature change of the legs is given by the expression

$$
\left\{\begin{array}{l}
P_{T x} \\
P_{T y} \\
P_{T \theta}
\end{array}\right\}=\left\{\begin{array}{c}
\sum_{r} \alpha_{r} \kappa_{r} \int_{o}^{l_{r}} T_{r}(s) d s \cdot \cos \varphi_{r} \\
\sum_{r} \alpha_{r} \kappa_{r} \int_{o}^{l} T_{r}(s) d s \cdot \sin \varphi_{r} \\
\sum_{r} \alpha_{r} \kappa_{r} x_{p r} \int_{o}^{l_{r}} T_{r}(s) d s \cdot \sin \left(\varphi_{r}-\Theta\right)
\end{array}\right\}
$$

where the integration of the temperature is over the length of the $\mathrm{r}^{\text {th }}$ leg. 
For a constant or uniform leg temperature change, $\mathrm{T}_{\text {or }}$,

$$
\int_{o}^{l_{r}} T_{r}(s) d s=l_{r} T_{o r}
$$

For a linear distribution of the temperature change over the length of the leg.

$$
\int_{o}^{l_{r}} T_{r}(s) d s=1 / 2 l_{r}\left(T_{1}+T_{2}\right)_{r}
$$

where $T_{1}$ and $T_{2}$ denote the temperature at the ends of the leg. 

